\title{
Ionic Conductivity of Bias Sputtered Lithium Phosphorus Oxy-nitride Thin Films
}

\section{Prabhu Doss Mani ${ }^{\mathrm{a}, \mathrm{c}^{*}}$, Shashank Saraf ${ }^{\mathrm{a}, \mathrm{c}}$, Virendra Singh ${ }^{\mathrm{a}, \mathrm{c}, \mathrm{f}}$, Maria}

\section{Real-Robert $^{\mathrm{b}}$, Arun Vijayakumar ${ }^{\mathrm{g}, \mathrm{h}}$, Steven J. Duranceau ${ }^{\mathrm{b}}$, Sudipta}

Seal ${ }^{\mathrm{a}, \mathrm{c}, \mathrm{d}, \mathrm{e}}$, Kevin R. Coffey ${ }^{\mathrm{a}, \mathrm{c}}$

${ }^{a}$ Department of Materials Science and Engineering, University of Central Florida, Orlando, FL - 32816

${ }^{b}$ Department of Civil, Environmental and Construction Engineering, University of Central Florida, Orlando, FL-32816

${ }^{c}$ Advanced Materials Processing and Analysis Center, University of Central Florida, Orlando, FL - 32816

${ }^{d}$ NanoScience Technology Center, University of Central Florida, Orlando, FL - 32816

${ }^{e}$ College of Medicine, University of Central Florida, Orlando, FL - 32827

${ }^{f}$ Schlumberger, 14910 Airline Road, Rosharon, TX - 77583

${ }^{g}$ Department of Electrical Engineering and Computer Science, University of Central Florida, Orlando, FL32816

${ }^{h}$ Samsung Austin Semiconductor, 12100 Samsung Blvd \#100, Austin, TX - 78754

*prabhudossmani@gmail.com

*Main address: Room 207, Engineering 1, Building 40, 12760 Pegasus Drive, Orlando, FL-32816, Tel:

+0014078230607, FAX: +0014078821462

*Present address: 12001 Solon Drive, Apt 201, Orlando, FL-32826

*Cell:+0014074590719 


\begin{abstract}
This manuscript reports a study of the ionic conductivity of radio frequency sputter deposited, lithium phosphorous oxy-nitride (LIPON), solid state electrolyte amorphous thin films. Films having compositions near $\mathrm{Li}_{2.5} \mathrm{PO}_{3.5} \mathrm{~N}_{0.5}$ were deposited under varying conditions of process gas, substrate bias, and deposition temperature. To understand the variations in ionic conductivity observed, the films were extensively characterized to examine structural and compositional differences, including examination by x-ray photoelectron spectroscopy (XPS), inductively coupled plasma optical emission spectroscopy, and spectroscopic ellipsometry. For the XPS study, depth profiling was used to allow a critical examination of the role of triply coordinated nitrogen in the ionic conductivity of LIPON. The highest ionic conductivity of $9.8 \mathrm{x}$ $10^{-6} \mathrm{~S} / \mathrm{cm}$ was obtained at an elevated deposition temperature and is correlated to a reduced density of defects, as indicated from the optical characterization.
\end{abstract}

Keywords: LiPON solid state electrolyte, XPS depth profiling, ionic conductivity and its correlation, RF reactive sputter deposition, ICP/OES chemical analysis, density of defects 


\section{Introduction}

Lithium phosphorous oxy-nitride (LiPON) is a widely studied and commercially used solid state electrolyte in lithium battery technology. LiPON films have a stable network, wide electrochemical window, negligible electronic conductivity, and a relatively high ionic conductivity with a nominal composition of $\mathrm{Li}_{(3-y)} \mathrm{PO}_{(4-x)} \mathrm{N}_{(1-x-y)} \cdot[1]$ For LiPON films prepared by magnetron sputter deposition, the role of processing parameters in determining film properties is complex. Thin films of LiPON were first characterized and investigated for thin film batteries by Bates et al., and were reported to be stable and compatible with Li anodes and to have a maximum ionic conductivity of $3.3 \times 10^{-6} \mathrm{~S} / \mathrm{cm} .[2,3]$ Bates et al. used radio-frequency (RF) sputter deposition to prepare thin film samples[2,3], a primary processing technique for LiPON thin films.[1-10] Other methods, such as, ion-beam assisted deposition (with ionic conductivity of $1.1 \times 10^{-6} \mathrm{~S} / \mathrm{cm}$ )[11], plasma assisted directed vapor deposition (between $10^{-7}$ and $10^{-8}$ $\mathrm{S} / \mathrm{cm})[12]$, and evaporation $\left(6 \times 10^{-7} \mathrm{~S} / \mathrm{cm}\right)[13]$ have also been used.

The RF sputtering technique commonly uses a lithium ortho-phosphate $\left(\mathrm{Li}_{3} \mathrm{PO}_{4}\right)$ target and a nitrogen sputtering process gas. Almost all prior reports of the ionic conductivity for RF sputtered LiPON thin films are in the range of $6 \times 10^{-7} \mathrm{~S} / \mathrm{cm}$ to $3 \times 10^{-6} \mathrm{~S} / \mathrm{cm}$. [1-13] The exception was the work of Chiu et al.[14] in which LiPON films were deposited by applying negative substrate bias and post annealing. In the study Chiu reported a highest ionic conductivity of $9.1 \times 10^{-6} \mathrm{~S} / \mathrm{cm}$ for unannealed films deposited at $-10 \mathrm{~V}$ substrate bias, which is still considerably lower than that of sulphide solid state electrolyte materials, which are in the range of $10^{-3} \mathrm{~S} / \mathrm{cm} .[15,16]$ Accordingly, a primary aim of this study was to further explore the potential of deposition process parameters (i.e., substrate biasing, substrate heating, process gas pressure) to further improve the ionic conductivity of LiPON. An additional aim of the study was an improved understanding of ionic conduction in LiPON and, specifically, to examine the role of triply coordinated nitrogen. This form of nitrogen bonding has been positively correlated 
to ionic conductivity by many prior workers but found to be absent in the NMR study of Stallworth et al.[17] This work reports a novel structure-processing-properties correlation based on the defect density and nitrogen coordination, the parametric effects of deposition conditions, and the ionic conductivity.

\section{Experimental Methods}

\subsection{Sample Structure:}

The sample top and bottom electrode areas and the leads consisted of patterned Pt with an intervening LiPON solid state electrolyte blanket film layer. Stainless steel contact masks were used to pattern the Pt depositions with the time of laboratory air exposure during the introduction or removal of the masks minimized (typically 60 seconds) to prevent oxidation/degradation of the LiPON layer. The primary sample preparation sequence started with the deposition of a $10 \mathrm{~nm}$ Ti seed layer and $150 \mathrm{~nm}$ of $\mathrm{Pt}$ for the bottom electrode, both through a contact mask. After removal of the mask, the LiPON electrolyte layer was deposited. Subsequently, a top electrode mask was placed over the sample and $100 \mathrm{~nm}$ Pt top electrode was deposited. A second LiPON "cap" layer of $200 \mathrm{~nm}$ was deposited on top of the wafer as a last step to serve as an encapsulant to further mitigate atmospheric degradation of the LiPON layer during storage and testing. Cross sectional scanning electron microscopy (SEM) images of this layer structure (prepared by sample fracture) are shown in Figures $4 a$ ) and $4 b$ ) for areas of LiPON sample M with and without the Pt electrodes, respectively. To provide sufficient LiPON material for the measurement of film density and for the extraction of material for chemical analysis, a second sample was made for each set of deposition conditions studied wherein a large area single layer blanket film of LiPON was deposited. 


\subsection{Sample Processing:}

The LiPON films were processed by reactive radio frequency (RF) magnetron sputtering of a lithium ortho-phosphate target of $99.9 \%$ purity (from SCl Engineered Materials, Inc.) using $99.999 \%$ purity nitrogen as a process gas. The films were deposited onto a silicon wafer substrate having thermally grown oxide surface layer providing electrical isolation from the substrate. A sputter deposition system with three sputtering sources in a confocal geometry was used for the depositions. The tilt angle of the sputter source was optimized to provide radially uniform LiPON film thickness on the substrate $(+/-3 \%$ on whole substrate and less than $+/-1 \%$ on the device area), which was rotated about its axis during the depositions. Preliminary work by the authors[18] identified a target RF power of 150 Watts with a $20 \mathrm{sccm}$ flow of nitrogen gas at 5 mTorr and a target to substrate (substrate center) distance of $\sim 12 \mathrm{~cm}$ as suitable fixed process parameters for use in the present investigation of substrate biasing, substrate heating, and process gas pressure.

With the confocal geometry, the amount of deposit can be radially balanced for uniform thickness by adjustment of the sputtering source angle of tilt, but radially non-uniform plasma bombardment on the substrate surface may still occur. As the target to substrate distance is longer from the center of the substrate holder compared to that of the periphery, a less energetic bombardment at the center of the substrate and a more energetic bombardment at the film outer diameter is expected for the films deposited without RF bias. Accordingly, a greater film adhesion at the outer diameter is expected compared to the center, and this was observed wherein the LiPON film at the center of the substrate holder was loosely adhered and tended to delaminate. Such occurrence increased the motivation for the investigation of RF bias during LiPON deposition.

To improve the film adhesion by providing a more uniform bombardment across the substrate surface, a RF substrate bias was applied to the substrate holder, increasing the 
density and acceleration voltage of the energetic ions in the plasma beneath the substrate holder. The strength of the bias was controlled by a constant power setting. The bias power levels investigated (with the corresponding bias acceleration voltage ranges tested) were: $0 \mathrm{~W}$ (15 to $18 \mathrm{~V}$ of plasma potential), $5 \mathrm{~W}$ (110 to $125 \mathrm{~V}), 10 \mathrm{~W}$ (135 to $155 \mathrm{~V}), 15 \mathrm{~W}$ (165 to $185 \mathrm{~V}$ ), and $20 \mathrm{~W}(195 \mathrm{~V}$ to $215 \mathrm{~V})$.

Indirect heating of the substrate surface $\left(200^{\circ} \mathrm{C}\right.$ to $\left.500^{\circ} \mathrm{C}\right)$ by halogen lamps irradiating the backside of the Inconel substrate holder was also used during deposition to observe its influence on the film properties.

\subsection{Sample Characterization:}

Amorphous LiPON thin films, lacking crystalline order, were expected on this study based on the work of others $[3,7-9,19,20]$ and it was confirmed in this work by X-ray diffraction and transmission electron microscopy analyses of selected samples. In addition, characterization of the other aspects of the sputtered LiPON thin films using various techniques to determine the thickness, stress, ionic conductivity and its activation energy, lithium to phosphorus (Li/P) atomic ratio, bonding information, film density, and density of defects was performed. The film density was determined from the film mass and volume. The film mass was calculated as the difference between the wafer mass measurements with and without the film present, and the film volume was calculated from the film area and thickness.

A JA Woollam M2000 spectroscopic ellipsometer was used to determine both the film thickness and its optical properties (i.e., refractive index, $n$, and extinction coefficient, k).[21] The multiple layers of the sample were modeled using the Cauchy and Urbach equations for the optical constants of the LiPON layer and using published values for the optical constants of the $\mathrm{SiO}_{2}$ layer and the silicon substrate.[22] The LiPON layer's optical properties are then determined by modeling consistent with the Kramers-Kronig relations[23,24]. 
The optical properties of an amorphous film can be used to understand the defects or irregularities in its bonding as has been done extensively for amorphous silicon, where defects are observed as electron states between the conduction and valance bands. [25] These bonding defects give rise to an "optical tail" or "Urbach tail[26]" in plots of the absorption coefficient, $\alpha=4 \pi k / \lambda$, as a function of photon energy. Equivalently, tails in plots of the extinction coefficient, $k$ as a function of wavelength are observed as indications of optically active defects in an amorphous structure. These defect states between the conduction and valance bands of an amorphous material also serve to narrow the effective band gap and Tauc's relation is commonly used to determine the effective optical band gap in a disordered or amorphous material:[27] The number of optically active defects per unit volume is expected to be proportional to the penetration depth, $\delta$, which is given by $\delta=1 / \alpha=\lambda / 4 \pi k$.

(a) Layer structure

\begin{tabular}{|c|}
\hline LiPON-cap \\
\hline $\mathrm{Pt}$ \\
\hline LiPON-electrolyte \\
\hline $\mathrm{Pt} / \mathrm{Ti}$ \\
\hline $\mathrm{SiO}_{2} / \mathrm{Si}$ \\
\hline
\end{tabular}

(b) Side view

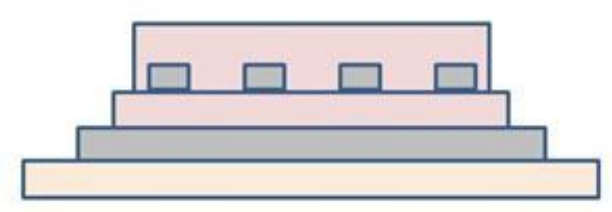

(c) Top view

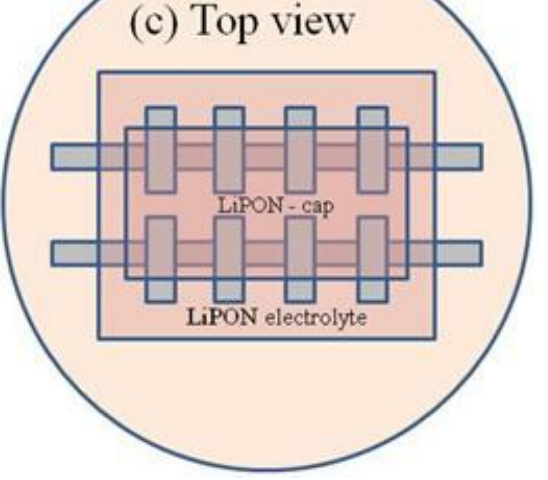

Figure 1 A metal/electrolyte/metal layered structure was used for ionic conductivity measurements. (a) is the layer structure, (b) a side view, and (c) is a top view showing the cross electrode geometry.

The LiPON thin film residual stress was determined by measurement of the substrate wafer's radius of curvature before and after film deposition using a Tencor Flexus FLX-2320 instrument. The wafers with blanket LiPON films were used for the stress measurements, and four radial scans through the center of the wafer at 45 degree separations were used to determine the average change in the substrate radius of curvature. The Stoney[28] formula was 
then used to calculate the biaxial stress state of the sputter deposited film using the biaxial elastic modulus of the substrate [1.805 $\times 10^{11} \mathrm{~Pa}$ for $\left.\mathrm{Si}(100)[29]\right]$,

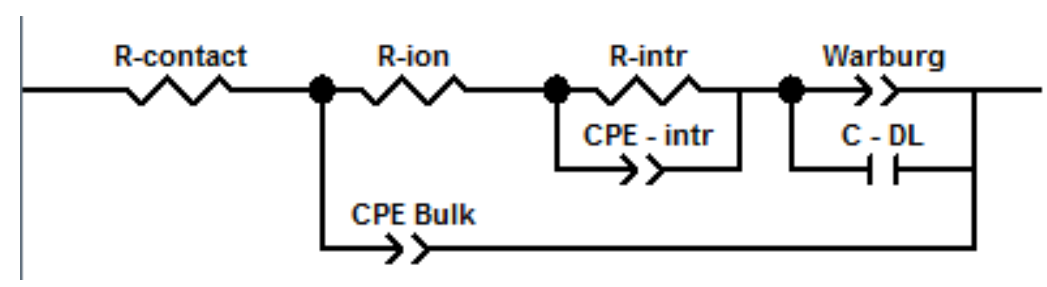

Figure 2 The equivalent circuit model used to extract ion transport resistance, R-ion, to determine the ionic conductivity. The other circuit elements are identified in the text

The ionic conductivity of the LiPON films was determined by measuring the impedance of metal/electrolyte/metal (Pt/LiPON/Pt) capacitive thin film structures as a function of frequency, a technique known as electrochemical impedance spectroscopy. In this technique, a signal voltage over a wide range of frequency is applied to the metal-electrolyte-metal structure, and the phase shift and amplitude (i.e., real and imaginary parts) of the signal current at each frequency are measured to give the impedance at that frequency, from which the ionic conductivity is determined. A Solartron 1260 impedance/gain-phase analyzer was used for this analysis. A metal/electrolyte/metal cross pattern structure used for the ionic conductivity measurements is shown in Figure 1. Note that each element to be measured is electrically isolated as shown in Figure 1c). Other sample geometries that allow multiple elements to form electrical series-parallel circuits, as reported by Fleutot et al. in their Figure 1[10], can result in measurement error for the intended element. Impedance data is normally obtained as Nyquist plots and the modeling software ZView was used for fitting the data to obtain electrolyte resistance and, hence, ionic conductivity.[30] The activation energy for the lithium ion conduction was calculated by fitting the ionic conductivity at four different temperatures (i.e., $21^{\circ} \mathrm{C}, 30^{\circ} \mathrm{C}, 40^{\circ} \mathrm{C}$, and $50^{\circ} \mathrm{C}$ ) to an Arrhenius temperature dependence. 
(a)

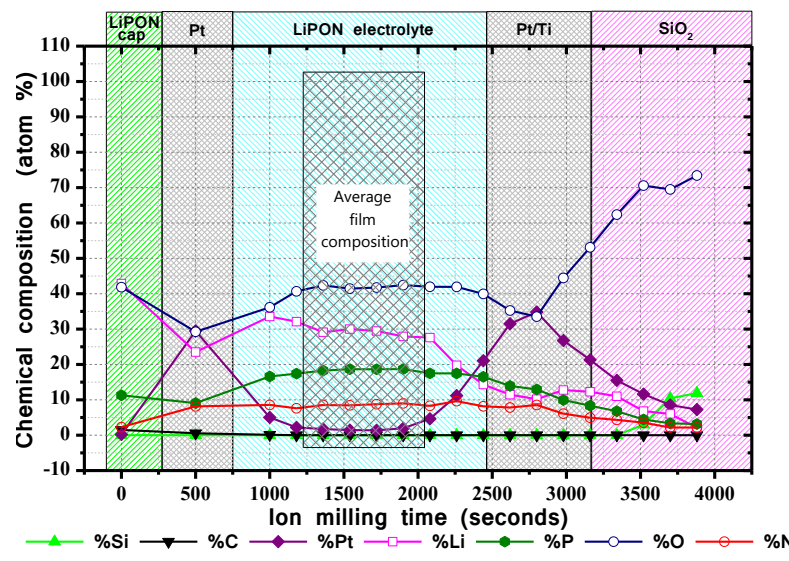

(c)

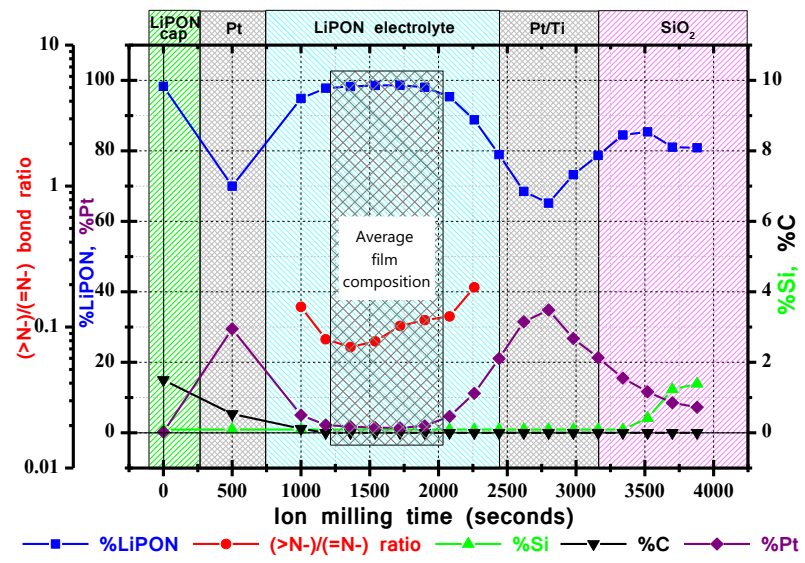

(e)

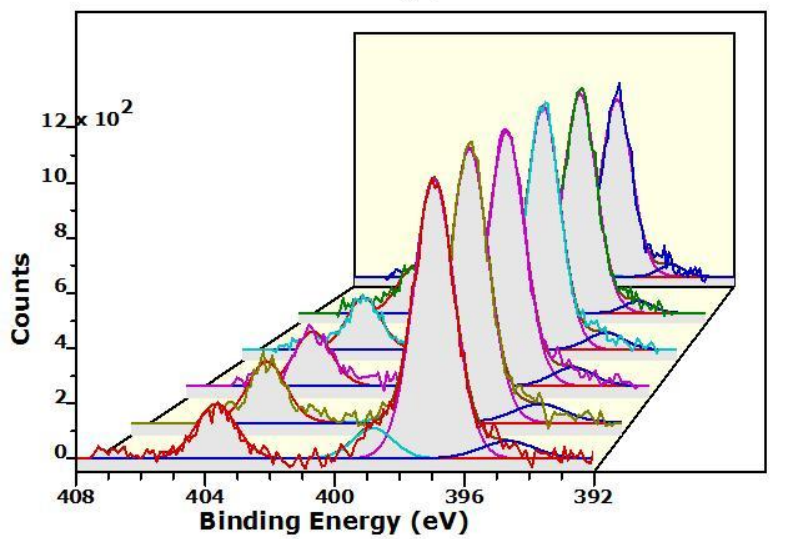

(b)

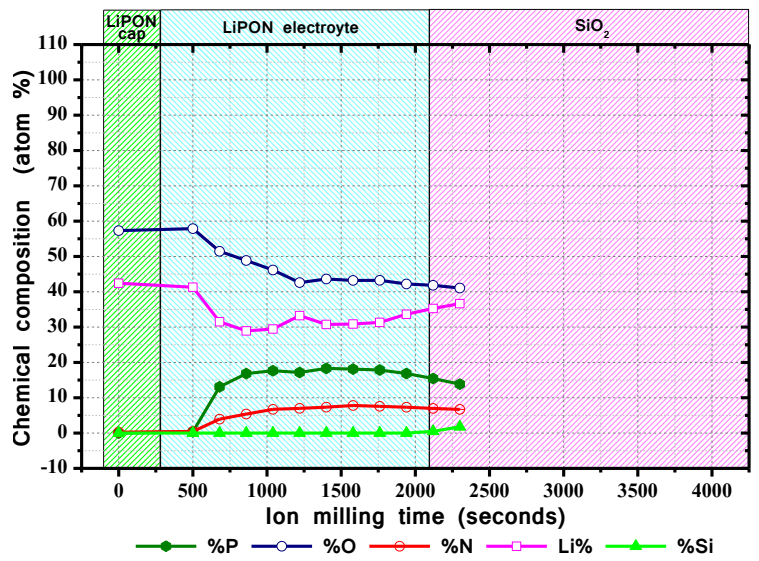

(d)

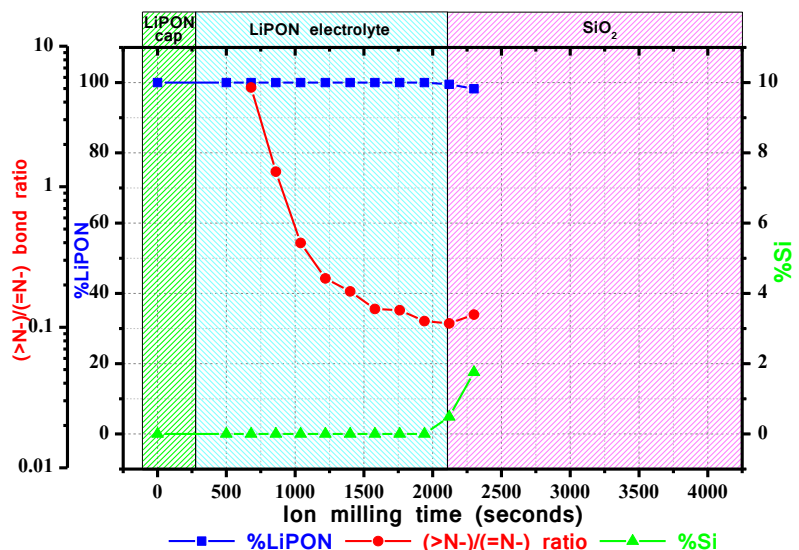

(f)

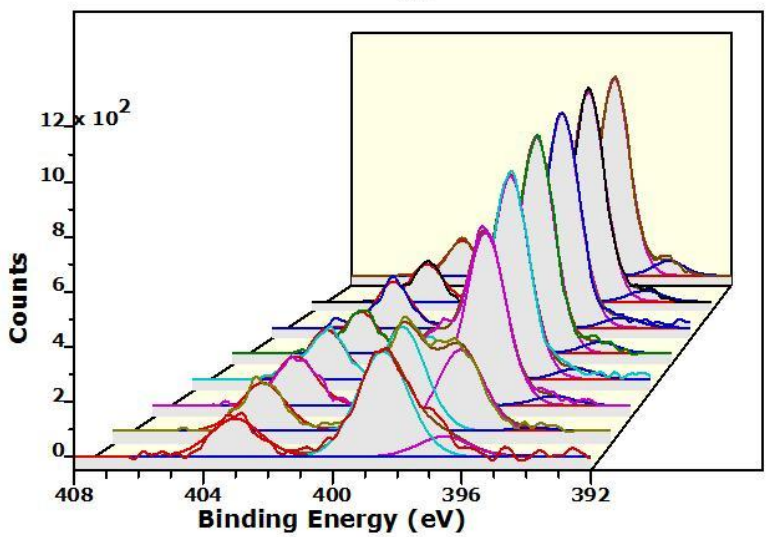

Figure 3 Results of the XPS depth profiling of sample G. Inset (a) shows the variation of composition as atomic percent as a function of ion milling time in an area with $\mathrm{Pt}$ electrodes. Inset (b) shows the equivalent depth profile of an adjacent area without Pt electrodes. Inset (c) shows \%LiPON, \%Pt, \%C, \%Si and the $(>\mathrm{N}-) /(=\mathrm{N}-)$ bond ratio as a function of ion milling time for an area with Pt electrodes. Inset (d) shows the \%LiPON, 
$\% \mathrm{Si}$ and the $(>\mathrm{N}-) /(=\mathrm{N}-)$ bond ratio for an adjacent area without Pt electrodes. Inset (e) shows the high resolution N1s scans from the area with Pt electrodes overlayed at a sequence of ion milling times to illustrate the relative consistancy of the $\mathbf{N}$ bonding with depth. Inset (f) shows the high resolution N1s scans from an adjacent area without Pt electrodes to illustrate the variation of $\mathbf{N}$ bonding in the upper portion of the LiPON layer.

An equivalent circuit model, as shown in Figure 2, for mixed ionic conduction was used to interpret the experimental results based on the work of Jamnik and Maier[31], Lai and Haile[32], and Donnelly and Randell[33]. In this circuit model, a constant phase element (CPEbulk) was used instead of bulk capacitance. An additional resistance (R-intr) with a CPE circuit (CPE-intr) was added to accommodate the interfacial or reactive layer. Warburg impedance (diffusional behavior) and a double layer capacitance (C-DL) were added in parallel to account for the contributions from the electrode interface. The contact lead resistance (R-contact) was also included in this model.

(a)

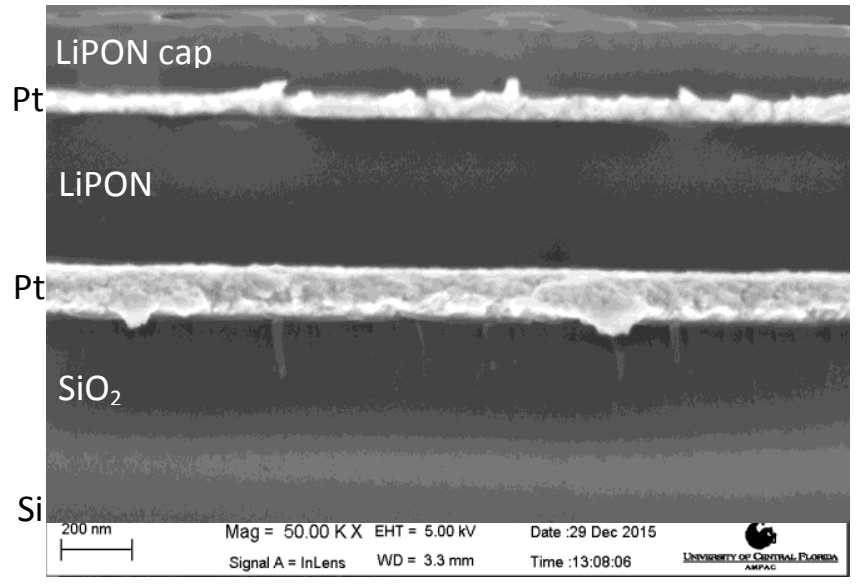

(b)

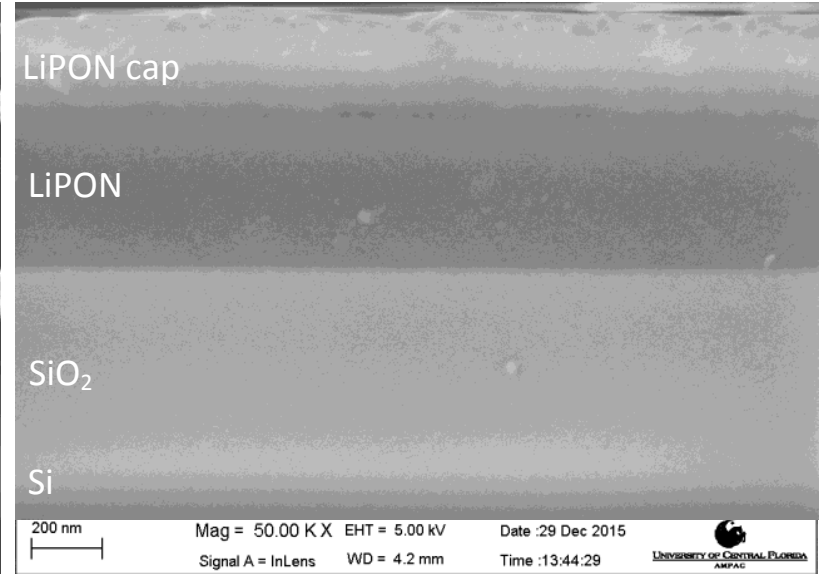

Figure 4 Cross-sectional SEM images of (a) device region showing LiPON cap layer/Pt/LiPON/Pt/SiO 2 and (b) adjacent non-device region showing LiPON cap layer/LiPON/SiO ${ }_{2}$. The exposed LiPON cap layer has greater roughness than the nonexposed LiPON electrolyte layer which is conformal to the layer below (Pt or $\left.\mathrm{SiO}_{2}\right)$. These images were prepared by fracture from sample $M$ and non-uniform fracture of the more ductile Pt layers is evident. 
The bond structure and associated elemental composition were studied using the Thermo Scientific ESCALAB-220Xi, an x-ray photoelectron spectrometer with Avantage software. The samples were irradiated from an Al- $\mathrm{K}_{\alpha}$ monochromatic X-ray source to a spot of $150 \mu \mathrm{m} \times 800 \mu \mathrm{m}$ with a residual vacuum of $8 \times 10^{-9}$ Torr or better. The measurements included compositional analysis after an initial Ar ion beam cleaning (and hence some erosion) of the sample surface and after additional Ar ion milling steps (at three minutes) throughout the depth of the film. The later step which is a depth profiling (using EX05 argon ion source) was done on both the Pt/LiPON/Pt device area and on the blanket film region without Pt electrodes immediately adjacent to the Pt/LiPON/Pt device (in order to compare with the published results).

The EX05 ion gun was maintained with a fixed beam energy of $3 \mathrm{kV}$ and a beam current of $\sim 1 \mu \mathrm{A}$ and was differentially pumped to maintain the base pressure at $\sim 5 \times 10^{-7}$ Torr or better during ion milling. The condenser and focus lens were fixed for all the scans. The ion milling was rastered on a sufficiently large area such that the X-ray irradiated area of the sample could be easily positioned within the rastered area to ensure that all photoelectrons captured were from a uniform depth of the etched region. The survey spectra were obtained (between $0 \mathrm{eV}$ and $1210 \mathrm{eV}$ ) with a pass energy of $50 \mathrm{eV}$ and the high resolution scans were obtained with $20 \mathrm{eV}$ pass energy. The high resolution scans include Li 1s, P 2p, O 1s, N 1s, Ar 2p, Pt 2p, Si $2 \mathrm{p}$, and $\mathrm{C} 1 \mathrm{~s} . \mathrm{C} 1 \mathrm{~s}(284.6 \mathrm{eV})$ was used as the reference voltage for surface scans and the $\mathrm{Ar}$ $2 p(241.9 \mathrm{eV}$ for Ar 2p3/2) was used as the reference voltage in depth profile scans; a charge neutralizer was not used and additional shifts in energy scale were observed. The data was analyzed using Casaxps software.[34] An average spectrum of profiles within the film was created to provide information representative of the bulk of the LiPON layer.

In development of the XPS studies the oxidation/degradation of exposed LiPON surfaces was noted. As an example, the compositional profiles of Sample G taken in the 
device region (with Pt electrodes) and in an adjacent blanket film region on the same wafer are shown in Figures $3 a$ ) and $3 b)$, respectively. For clarity, the depth ranges corresponding to each layer present in the profile are indicated in the figures. Significant differences between the LiPON film composition in the Pt/LiPON/Pt device areas and that of the adjacent LiPON blanket film were observed for all samples.

In spite of the presence of a LiPON cap layer, the composition of the near-surface region of the film areas without the Pt electrodes appears to be significantly different than that of the majority of the film. The composition of the LiPON cap layer and the upper portions of the LiPON electrolyte layer in the regions of each sample without Pt electrodes are oxidized, having high lithium and oxygen concentration and correspondingly low nitrogen and phosphorus content. This oxidized surface occurred in spite of sample storage in high purity $\operatorname{Ar}$ (nominally 99.999\%) with limited ambient air exposure during ionic conductivity measurements (less than 12 hours in all cases). The type of nitrogen bonding present also showed a difference with depth in the regions without Pt electrodes, with a higher ratio of triply coordinated nitrogen to doubly coordinated nitrogen $(>\mathrm{N}-) /(=\mathrm{N}-)$ in the near-surface region than in the rest of the film layer. For Sample G, this ratio is shown for the device and adjacent areas on an additional logarithmically scaled axis in Figures $3 c$ ) and 3d), respectively. For the adjacent area without the Pt electrodes the ratio drops from a value greater than 5.0 just below the surface of the LiPON electrolyte layer (after 680 seconds of Ar ion etching) to less than 0.2 in the bulk of the LiPON electrolyte layer (after 1400 seconds of Ar ion etching). For the Pt/LiPON/Pt device region the result of the XPS depth profiling is very different, as shown in Figure 3c). In this case, the ratio of triply coordinated nitrogen to doubly coordinated nitrogen stays in the range of 0.19 to 0.07 in the electrolyte layer. This indicates that degradation of the surface of the LiPON electrolyte layer occurred in areas not protected by Pt electrodes, in spite of the presence of a LiPON encapsulant layer. 
There have been prior XPS studies of bonding in LiPON films by various authors.[5,6,8$10,14,19,20]$ However, depth profiling was not used in their studies and hence the surface areas sampled were those without the protection of Pt electrodes. These prior studies sampled areas adjacent to the devices or areas on separate wafers. In the depth profiling study presented in this paper, it is clear that the prior studies of the near surface regions without depth profiling are subject to surface degradation. The extent of surface degradation can be presumed to be variable, dependent on sample handling and storage conditions. The ratio of triply-coordinated to doubly-coordinated nitrogen $(>\mathrm{N}-) /(=\mathrm{N}-)$ reported in these prior studies of sputter deposited LiPON films is also variable, from a low of 0.15 to a high of 3.33. Many of these prior works considered the triply coordinated nitrogen significant to the ionic conductivity; however, the details of the sample handling (i.e., exposure to air) and the extent to which any ion beam cleaning of the surface was performed prior to acquisition of the XPS spectra are absent. However, the range of ratios observed in these prior works, having potential (but unknown) extents of surface oxidation/degradation, are consistent with those that were found in this study at or slightly below the surface in areas not protected by Pt electrodes (e.g., Figure 3d). However, the depth profiling of Pt encapsulated areas in this study has shown that the above reported values are not representative of the device regions (as shown in Figure 3c). These differences in the triply coordinated and doubly coordinated nitrogen in the device and non-device areas are further evident in the XPS spectra of the relevant energy ranges shown in Figures 3e) and 3f) respectively. Moreover, the cross-sectional SEM images shown in Figures 4a) and $4 b$ ) of the device region and adjacent region, respectively, show that the LiPON cap layer is rougher whereas the protected LiPON electrolyte layer is considerably smoother and conformal to layer underneath ( $\mathrm{Pt}$ bottom electrode or the $\mathrm{SiO}_{2}$ layer). From this, it can be concluded that ex-situ XPS compositional studies without depth profiling of the device regions are likely not an accurate representation of the composition and bonding present in the LiPON 
electrolyte layer of the device regions and only data from the Pt/LiPON/Pt areas will be used to understand Li ion conductivity in this report.

(a)

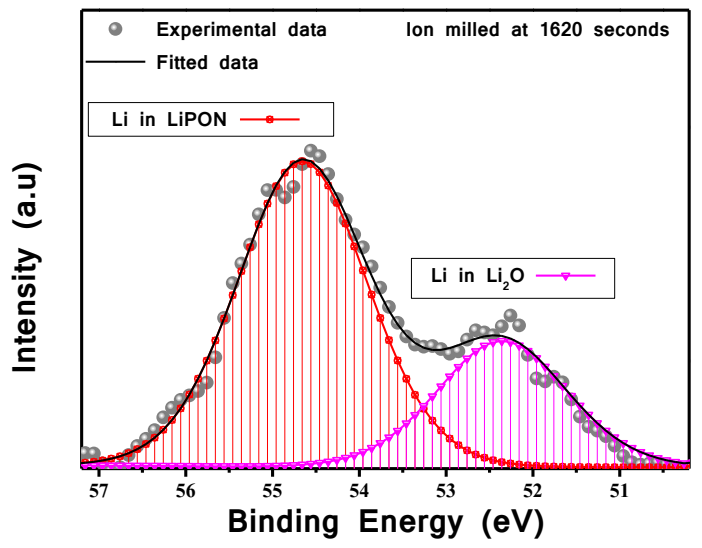

(c)

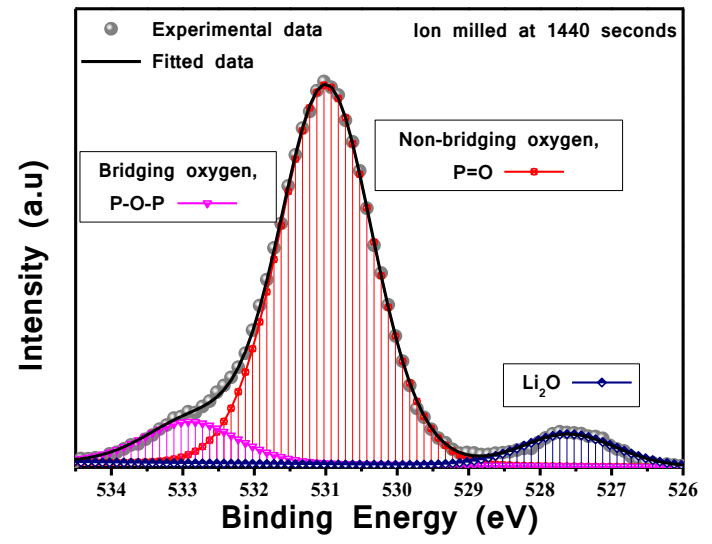

(b)

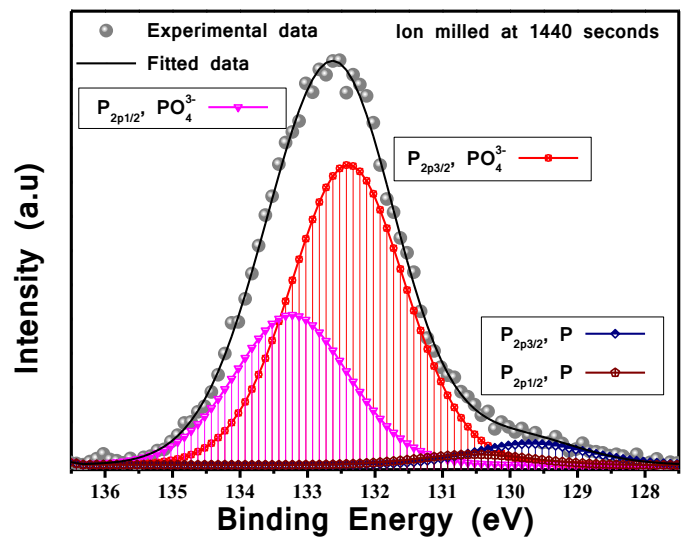

(d)

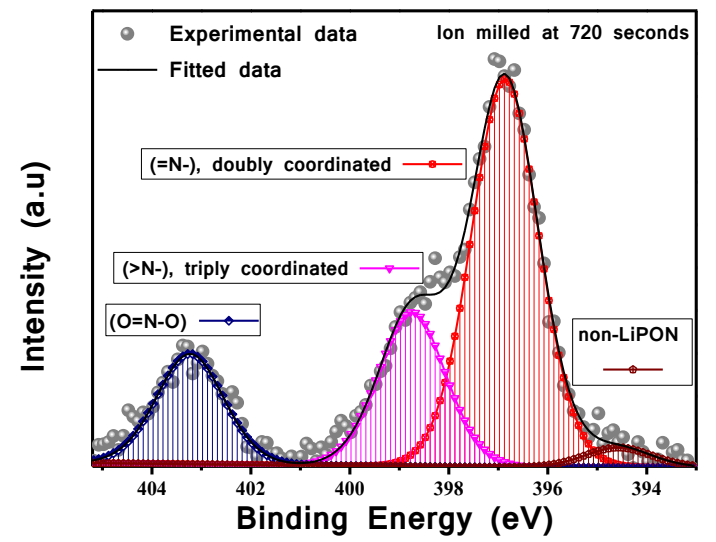

Figure 5 Examples of the deconvolution of the high resolution XPS spectra from sample G of Li1s, O1s, N1s and P2p scans are given by insets (a), (b), (c) and (d), respectively. The attribution of the peaks to different bonds is given in the text.

Table 1 Samples identified as $A$ to $O$ are processed at the conditions of substrate bias power, deposition temperature, process gas type, process gas pressure and flow as given. Additionally, the deposition rate for each sample, calculated from the LiPON electrolyte layer deposition time and thickness, is also included. Results of characterization of LiPON samples $A$ through $O$. The film properties given are the ionic conductivity, the activation energy for the ionic conduction, the thin film intrinsic stress, (developed during deposition and cooling), the film density, the extinction coefficient (k) at $246 \mathrm{~nm}$, the penetration depth at $246 \mathrm{~nm}$ and the optical band gap energy. 
Representative deconvolved XPS spectra of the Li1s, P2p, O1s, and N1s peak regions are given in Figures 5 a), b), c), and d), respectively. The Li1s spectrum shown in Figure 5a) has two peaks at $54.7 \mathrm{eV}$ and at $52.4 \mathrm{eV}$. The peak at $54.7 \mathrm{eV}$ can be assigned to Li bonding in 
LiPON and the one at $52.4 \mathrm{eV}$ can be assigned to $\mathrm{Li}$ bonding to oxygen ( $\mathrm{Li}-\mathrm{O})$ as in $\mathrm{Li}_{2} \mathrm{O}$, due to the $\sim 2.3 \mathrm{eV}$ difference in the binding energy between the two peaks is.[35-38] The phosphorus P2p spectrum in Figure $5 b$ ) has four peaks representing both the $2 p_{1 / 2}$ and $2 p_{3 / 2}$ contributions to the phosphorus bonding in $\mathrm{PO}_{4}{ }^{3-}$ and to the reduced phosphorous (zero valence) bonding. For the $\mathrm{PO}_{4}{ }^{3-}$ environment, the $\mathrm{P} 2 \mathrm{p}_{3 / 2}$ peak was observed at $132.4 \mathrm{eV}[10,20]$ and the $\mathrm{P} 2 \mathrm{p}_{1 / 2}$ contribution was $0.84 \mathrm{eV}$ higher, at $133.24 \mathrm{eV}$. For the reduced phosphorus environment, the P2 $p_{3 / 2}$ peak was observed at 129.7 eV[39,40] and the $\mathrm{P} 2 \mathrm{p}_{1 / 2}$ contribution was observed at $130.54 \mathrm{eV}$. The O1s spectrum in Figure 5c) clearly shows three peaks upon deconvolution; bridging oxygen $\mathrm{P}-\mathrm{O}-\mathrm{P}(\mathrm{BO})$ at $532.9 \mathrm{eV}$, non-bridging oxygen $\mathrm{P}=\mathrm{O}(\mathrm{NBO})$ at $531 \mathrm{eV}$, and a weaker peak of $\mathrm{Li}_{2} \mathrm{O}$ bonding at $527.7 \mathrm{eV}$. The $\mathrm{BO}$ and NBO peak identifications are consistent with prior reports of alkali bulk phosphate glasses[41] and LiPON films[38]. The $\mathrm{Li}_{2} \mathrm{O}$ bonding peak at $527.7 \mathrm{eV}$ in the $\mathrm{O} 1 \mathrm{~s}$ spectrum has also been described by other authors.[35-37] The $\mathrm{N} 1 \mathrm{~s}$ spectrum in Figure $5 \mathrm{~d})$ was deconvolved into four peaks; an $(\mathrm{O}=\mathrm{N}-\mathrm{O})$ bonding peak at 403.2 eV[5], a (>N-), triply coordinated nitrogen bonding peak at 398.7 eV[42], a (=N-), doubly coordinated nitrogen peak at $396.9 \mathrm{eV}$ [42], and a weaker unidentified peak at $394.6 \mathrm{eV}$ that has also been observed by others[5].

\subsection{ICP-OES method development for sample digestion and experimental} analysis:

The lithium to phosphorus $(\mathrm{Li} / \mathrm{P})$ atomic ratio was determined using inductively coupled plasma-optical emission spectroscopy (ICP-OES). Prior to this analysis, samples were digested using a method developed specifically for LiPON samples. A Perkin-Elmer 2100 DV ICP-OES system was used to determine the average Li/P atomic ratio in LiPON films. A digested sample was introduced at $1.5 \mathrm{~mL} / \mathrm{min}$ into a cyclonic spray chamber through a Meinhard Type C concentric glass nebulizer for aerosol generation. The nebulizer flow rate was set at 0.7 $\mathrm{mL} / \mathrm{min}$, and a sample aerosol was carried and injected into the plasma within a tulip quartz 
torch through an alumina injector. The plasma parameters were set at 1400 Watts of RF power with $15 \mathrm{~L} / \mathrm{min}$ of plasma flow and $0.2 \mathrm{~L} / \mathrm{min}$ of auxiliary flow. In the plasma, sample molecules were ionized and subsequently produced ionic optical emission spectra which were detected using a scanning charge-coupled device array detector. Lithium was measured at $670.8 \mathrm{~nm}$ using the radial window, while phosphorus was detected at $213.6 \mathrm{~nm}$ using the axial window.

Table 2 Compositional measurements of Samples A through O. The XPS measured elemental compositions in atomic percentages of $\mathrm{Li}, \mathrm{P}, \mathrm{O}$, and $\mathrm{N}$ together with the derived stoichiometry of LiPON films are given, along with the $\mathrm{Li} / \mathrm{P}$ atomic ratios calculated from XPS and from ICP/OES measurements.

\begin{tabular}{|c|c|c|c|c|c|c|c|}
\hline \multirow{2}{*}{ Samples } & \multicolumn{5}{|c|}{ XPS analysis } & \multicolumn{2}{|c|}{$\mathrm{Li} / \mathrm{P}$ atomic ratio } \\
\hline & $\% \mathrm{Li}$ & $\% \mathbf{P}$ & $\% 0$ & $\% N$ & Stoichiometry & XPS & ICP/OES \\
\hline $\mathbf{A}$ & 32.7 & 16.1 & 47.1 & 4.11 & $\mathrm{Li}_{2.04} \mathrm{P}^{\mathrm{O}_{2.93}} \mathrm{~N}_{0.26}$ & 2.04 & 2.98 \\
\hline B & 28.1 & 15.6 & $\overline{51.4}$ & 4.9 & $\mathrm{Li}_{1.81} \mathrm{P}^{\mathrm{O}_{3.30}} \mathrm{~N}_{0.31}$ & 1.81 & 3.14 \\
\hline $\bar{C}$ & 33.6 & 15.0 & 47.3 & 4.1 & $\mathrm{Li}_{2.24} \mathrm{P}_{3.15} \mathrm{~N}_{0.28}$ & 2.24 & 3.60 \\
\hline 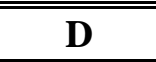 & 35.8 & 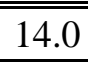 & 466.3 & 3.9 & 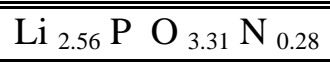 & 2.56 & 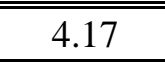 \\
\hline $\bar{E}$ & 32.6 & 14.3 & 499.4 & 3.7 & $\overline{\mathrm{Li}_{2.27}} \mathrm{P} \mathrm{O}_{3.45} \mathrm{~N}_{0.26}$ & 2.27 & 4.54 \\
\hline $\mathbf{F}$ & 31.4 & 18.3 & 42.3 & 8.0 & $\mathrm{Li}_{1.72} \mathrm{P}^{-} \mathrm{O}_{2.32} \mathrm{~N}_{0.44}$ & 1.72 & 3.32 \\
\hline$\overline{\bar{G}}$ & 29.4 & 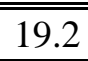 & "42.8 & 8.7 & 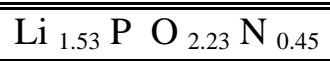 & 1.53 & 2.76 \\
\hline$\overline{\mathrm{H}}$ & N/A & N/A & N/A & N/A & N/A & N/A & 2.41 \\
\hline $\bar{I}$ & 27.1 & 19.6 & 433.0 & 10.3 & 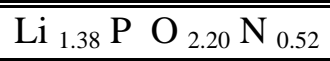 & 1.38 & 2.38 \\
\hline $\mathbf{J}$ & N/A & $\mathrm{N} / \mathrm{A}$ & N/A & N/A & N/A & $\mathrm{N} / \mathrm{A}$ & 4.09 \\
\hline$\overline{\bar{K}}$ & N/A & N/A & N/A & N/A & N/A & $\overline{\mathrm{N} / \mathrm{A}}$ & 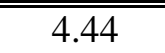 \\
\hline $\bar{L}$ & 29.4 & 16.4 & 48.2 & 6.0 & $\mathrm{Li}_{1.79} \mathrm{PO}_{2.95} \mathrm{~N}_{0.37}$ & 1.79 & $\mathrm{~N} / \mathrm{A}$ \\
\hline $\bar{M}$ & 26.4 & 16.3 & 50.5 & $\overline{6.8}$ & $\mathrm{Li}_{1.61} \mathrm{P}^{\mathrm{O}_{3.09}} \mathrm{~N}_{0.41}$ & 1.61 & N/A \\
\hline$\overline{\mathbf{N}}$ & 24.4 & 18.2 & 48.9 & 8.5 & $\overline{L L i}_{1.34} \mathrm{P} \mathrm{O}_{2.68} \mathrm{~N}_{0.47}$ & $\overline{\mid l 1.34}$ & N/A \\
\hline $\bar{O}$ & N/A & N/A & N/A & N/A & N/A & N/A & N/A \\
\hline
\end{tabular}

A digestion method prior to the ICP-OES analysis was developed to reliably extract the target metals from the LiPON sample. The method developed consisted of digesting the sample in $5 \% \mathrm{HNO}_{3}$ at $95^{\circ} \mathrm{C}$ for one hour, and this was compared to a previously published digestion method in $20 \% \mathrm{HNO}_{3}$ at $75^{\circ} \mathrm{C}$ by Kim.[12] These two methods were quantitatively compared by digesting known amounts of $\mathrm{Li}_{3} \mathrm{PO}_{4}$ powder (99.9\% purity, Sigma Aldrich) and 
analyzing for Li and P by ICP-OES. The results were assessed based on accuracy (\%Recovery of the actual lithium and phosphorus measured as compared to the standard $\left.\mathrm{Li}_{3} \mathrm{PO}_{4}\right)$ and precision (\%RSD of duplicate samples). The acceptable values for \%Recovery range from 80 to $120 \%$ with $\leq 10 \%$ for $\%$ RSD. The developed digestion method showed average recoveries of $92 \%(n=3)$ with $3 \% R S D$ for Li and $78 \%(n=3)$ with $4 \% R S D$ for P. These results, especially \%Recovery, are better than the published method which showed 87 \%Recovery $(n=3)$ with 1 \%RSD for lithium and 73 \%Recovery $(n=3)$ with $3 \%$ RSD for phosphorus. Therefore, sample digestion using $5 \% \mathrm{HNO}_{3}$ at $95^{\circ} \mathrm{C}$ for one hour digestion procedure was adopted for the analysis of the LiPON thin film samples.

Table 3 Lithium and nitrogen bonding characteristics of samples A through $\mathbf{N}$. A comparison of the amount of the two types of lithium bonds observed in the XPS characterization ( $\mathrm{Li}$ bonding in LiPON and lithium bonded to just oxygen (Li2O) as in non-LiPON) and the amount of the three types of LiPON nitrogen bonds $(\mathrm{O}=\mathrm{N}-\mathrm{O}),(>\mathrm{N}-)$, $(=\mathrm{N}-)$, and the $(>\mathrm{N}-) /(=\mathrm{N}-)$ bonding ratio. Also given is the amount of the unidentified nitrogen bond type, classified as non-LiPON.

\begin{tabular}{|c|c|c|c|c|c|c|c|}
\hline \multirow{3}{*}{ Samples } & \multicolumn{2}{|c|}{$\% \mathrm{Li}$} & \multicolumn{5}{|c|}{$\% \mathrm{~N}$} \\
\hline & \multirow{2}{*}{$\frac{\% \mathrm{LiPON}}{\mathrm{Li}^{+}}$} & \multirow{2}{*}{$\begin{array}{c}\left(\mathrm{Li}_{2} \mathrm{O}\right) \\
\text { \%non-LiPON }\end{array}$} & \multicolumn{4}{|c|}{$\%$ LiPON } & \multirow{2}{*}{$\begin{array}{c}\text { (Unidentified } \\
\text { nitrogen), } \\
\text { \% non-LiPON }\end{array}$} \\
\hline & & & $(\mathrm{O}=\mathrm{N}-\mathrm{O})$ & $(=\mathrm{N}-)$ & $(>\mathrm{N}-)$ & $(>\mathrm{N}-) /(=\mathrm{N}-)$ & \\
\hline $\mathbf{A}$ & 24.7 & 8.1 & 0.9 & 2.5 & 0.4 & 0.15 & 0.4 \\
\hline B & 23.5 & 4.7 & 0.9 & 3.1 & 0.4 & 0.12 & 0.5 \\
\hline $\mathrm{C}$ & 22.8 & 10.7 & 0.7 & 2.6 & 0.2 & 0.06 & 0.7 \\
\hline D & 24.2 & 11.5 & 0.7 & 2.2 & 0.2 & 0.11 & 0.7 \\
\hline $\mathbf{E}$ & 24.7 & 7.8 & 0.8 & 2.1 & 0.3 & 0.15 & 0.6 \\
\hline $\mathbf{F}$ & 28.3 & 3.1 & 1.4 & 5.5 & 0.6 & 0.10 & 0.6 \\
\hline $\mathbf{G}$ & 28.0 & 1.4 & 1.2 & 6.4 & 0.6 & 0.09 & 0.4 \\
\hline I & 24.3 & 2.8 & 1.2 & 8.1 & 0.5 & 0.06 & 0.4 \\
\hline $\mathbf{L}$ & 25.4 & 4.0 & 0.9 & 4.3 & 0.4 & 0.10 & 0.3 \\
\hline $\mathbf{M}$ & 26.2 & 0.2 & 1.0 & 4.9 & 0.3 & 0.07 & 0.5 \\
\hline$\overline{\mathbf{N}}$ & 22.5 & 1.8 & 1.3 & 5.8 & "0.6 & "0.11 & 0.8 \\
\hline
\end{tabular}

Table 4 Phosphorous and oxygen bonding characteristics of samples A through $\mathbf{N}$. The amounts of the two types of phosphorus bonds (phosphate PO43- and the reduced phosphorus) and the amount of the oxygen bonded in phosphate P043- (bridging 
oxygen (-O-) and non-bridging oxygen $(\mathrm{P}=\mathrm{O})$ ) are given. Also given is the amount of oxygen bonded with lithium (Li2O, non-LiPON).

\begin{tabular}{|c|c|c|c|c|c|}
\hline \multirow[b]{3}{*}{ Samples } & \multicolumn{2}{|c|}{$\% \mathbf{P}$} & \multicolumn{3}{|c|}{$\% 0$} \\
\hline & \multirow{2}{*}{$\begin{array}{c}\text { \% LiPON } \\
\mathrm{PO}_{4}{ }^{3-}, \\
\text { Phosphate } \\
\text { network }\end{array}$} & \multirow[b]{2}{*}{ \%non-LiPON } & \multicolumn{2}{|c|}{ \%LiPON } & \multirow[b]{2}{*}{ \%non-LiPON } \\
\hline & & & $\begin{array}{l}\text { BO, } \\
\text { bridging oxygen }\end{array}$ & $\begin{array}{c}\mathrm{NBO}, \\
\text { non-bridging } \\
\text { oxygen }\end{array}$ & \\
\hline $\mathbf{A}$ & 15.5 & 0.5 & 4.5 & 38.7 & 3.9 \\
\hline B & 14.9 & 0.6 & 3.8 & 44.7 & 2.9 \\
\hline $\mathbf{C}$ & 14.4 & 0.6 & 2.6 & 39.0 & 5.8 \\
\hline $\bar{D}$ & 13.5 & 0.5 & 3.0 & 38.3 & 4.9 \\
\hline $\mathbf{E}$ & 13.8 & 0.5 & 3.2 & 41.9 & 4.3 \\
\hline $\mathbf{F}$ & 16.8 & 1.5 & 2.0 & 38.0 & 2.4 \\
\hline $\bar{G}$ & 17.7 & 1.5 & 2.4 & 38.9 & 1.5 \\
\hline I & 16.4 & 3.2 & 1.7 & 38.0 & 3.3 \\
\hline $\mathbf{L}$ & 48.2 & 6.0 & 3.5 & 41.9 & 2.8 \\
\hline $\mathbf{M}$ & 50.5 & 6.8 & 2.3 & 46.8 & 1.4 \\
\hline $\mathbf{N}$ & 48.9 & 8.5 & 3.2 & 41.9 & 3.8 \\
\hline
\end{tabular}

Table 5 Molar volume calculations for samples A through I from the atomic weights of $\mathrm{Li}$, $P, O$, and $N$ in LiPON and the measured film density.

\begin{tabular}{|c|c|c|c|c|c|c|c|c|}
\hline Samples & $\begin{array}{c}\mathbf{L i} \\
(\mathbf{g} / \mathbf{m o l e})\end{array}$ & $\begin{array}{c}\mathbf{P} \\
(\mathbf{g} / \mathbf{m o l e})\end{array}$ & $\begin{array}{c}\mathbf{O} \\
(\mathbf{g} / \mathbf{m o l e})\end{array}$ & $\begin{array}{c}\mathbf{N} \\
(\mathbf{g} / \mathbf{m o l e})\end{array}$ & $\begin{array}{c}\text { Total } \\
(\mathbf{g} / \mathbf{m o l e})\end{array}$ & $\begin{array}{c}\text { Film } \\
\text { density } \\
(\mathbf{g} / \mathbf{c c})\end{array}$ & $\begin{array}{c}\text { Atomic } \\
\text { volume } \\
\text { mole/cc }\end{array}$ & $\begin{array}{c}\text { Molar } \\
\text { volume } \\
\text { cc/mole }\end{array}$ \\
\hline $\mathbf{A}$ & 2.29 & 4.98 & 7.53 & 0.58 & 15.38 & 2.24 & 0.15 & 6.87 \\
\hline \hline $\mathbf{B}$ & 1.97 & 4.82 & 8.22 & 0.69 & 15.70 & 2.15 & 0.14 & 7.30 \\
\hline \hline $\mathbf{C}$ & 2.35 & 4.65 & 7.57 & 0.58 & 15.15 & 2.13 & 0.14 & 7.11 \\
\hline \hline $\mathbf{D}$ & 2.50 & 4.34 & 7.41 & 0.55 & 14.80 & 2.18 & 0.15 & 6.79 \\
\hline $\mathbf{F}$ & 2.28 & 4.44 & 7.91 & 0.52 & 15.15 & 2.21 & 0.15 & 6.85 \\
\hline \hline $\mathbf{G}$ & 2.20 & 5.65 & 6.77 & 1.12 & 15.75 & 2.28 & 0.14 & 6.91 \\
\hline \hline $\mathbf{I}$ & 2.06 & 5.95 & 6.84 & 1.21 & 16.06 & 2.43 & 0.15 & 6.61 \\
\hline
\end{tabular}


(a)

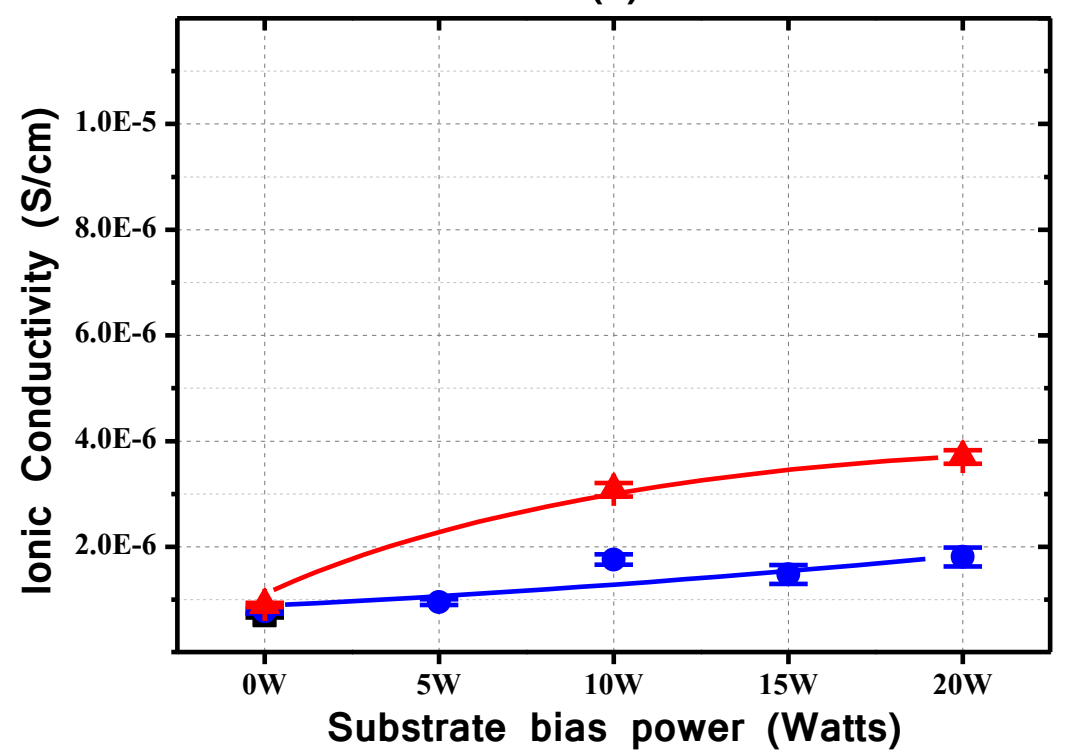

- $5 \mathrm{mT}-\mathrm{Ar}, 24^{\circ} \mathrm{C} \longrightarrow 5 \mathrm{mT}-\mathrm{N}_{2}, 24^{\circ} \mathrm{C} \triangle 5 \mathrm{mT}-\mathrm{N}_{2}, 300^{\circ} \mathrm{C}$

(b)

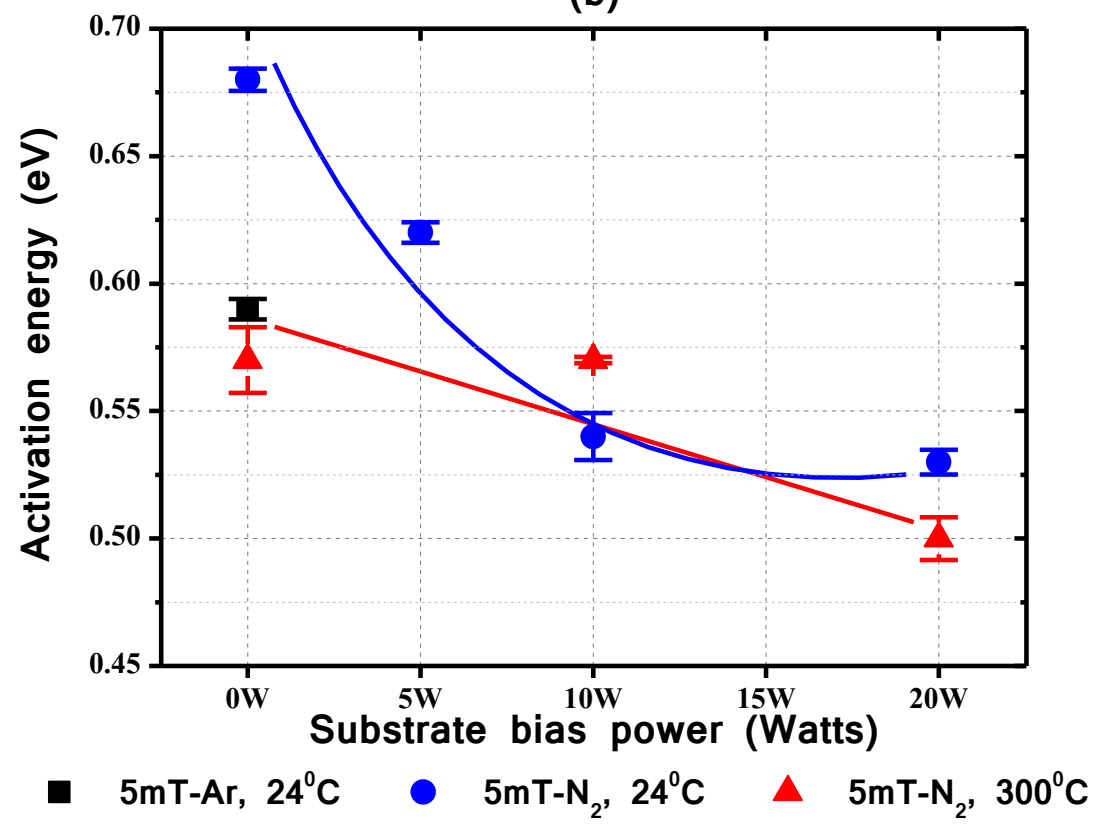

Figure 6 Inset (a) shows the ionic conductivity and inset (b) the activation energy of ionic conduction for LiPON films as a function of substrate bias power. Please note that the curved lines are shown to guide the eye. 


\section{Results}

The deposition process conditions for the LiPON films in this study and its properties are presented in Table 1. LiPON Samples A through E were deposited at a RF bias power levels ranging from zero $(0 \mathrm{~W})$ to $20 \mathrm{~W}$. Samples $\mathrm{F}$ through I were deposited at deposition temperatures ranging from $200^{\circ} \mathrm{C}$ to $500^{\circ} \mathrm{C}$. Also included in Table 1 are the samples deposited at increased $\mathrm{N}_{2}$ gas pressure during deposition (Samples $\mathrm{J}$ and $\mathrm{K}$ ), samples deposited to explore combinations of bias and increased deposition temperature (Samples $L, M$, and $N$ ), and a sample deposited with $\mathrm{Ar}$ instead of $\mathrm{N}_{2}$ to provide a $\mathrm{Li}_{3} \mathrm{PO}_{4}$ film for comparison (Sample O). The deposition rate measured for each set of deposition conditions is also given in Table 1, wherein can be seen that the deposition rate decreases as bias power or deposition temperature are increased.

The characteristic properties of samples A through $O$ that are listed in Table 1 include ionic conductivity, activation energy for ionic conduction, film stress, film density, and selected optical properties. Notably, Sample I, deposited at the highest temperature of $500^{\circ} \mathrm{C}$ has the highest ionic conductivity. To calculate film density, the differences in weight of the LiPON films before and after the deposition were measured and the volume is calculated from the film thickness and the area of the substrate.

Tables 2, 3, and 4 reports the XPS results from depth profiling of the sample areas that were protected by Pt electrodes, where ionic conductivity was measured. For XPS measurements, the included samples are the substrate bias series and the samples deposited with higher temperatures at $10 \mathrm{~W}$ bias power. Table 2 includes the composition, in atomic percent, of samples $A$ through $L$, as determined by XPS. Additionally, the Li/P atomic ratio as determined by ICP/OES is included in the table. A Li/P atomic ratio calculated from the XPS data is approximately $40 \%$ lower than that determined by ICP/OES, presumably due to the preferential sputtering of Li during profiling[43]. The XPS values given in Table 2 are an 
average of measurements from within the bulk of the LiPON film in the Pt/LiPON/Pt device areas, which is most representative of the material whose ionic conductivity was measured. As an example, the values in the cross-hatched region in Figure 3a) were averaged to provide the compositional information for sample G shown in Table 2.

Tables 3 and 4 present the results of the deconvolution of the XPS high resolution scans of the Li 1s, P 2p, O 1s, and N 1s peaks. The Li 1s peak was further analyzed to deconvolute the contribution of $\mathrm{Li}$ bonded in $\mathrm{LiPON}$ and $\mathrm{Li}$-oxygen bonding $\left(\mathrm{Li}_{2} \mathrm{O}\right)$, and these fractions are shown in Table 3 as percentages of the overall film composition $(\mathrm{Li}+\mathrm{P}+\mathrm{O}+\mathrm{N})$. Similarly, the $\mathrm{N}$ 1s peak was deconvoluted into four peaks. Three of these peaks are associated with LiPON; nitrogen bonded to oxygen $(\mathrm{O}=\mathrm{N}-\mathrm{O})$, triply coordinated nitrogen bonded to phosphates, $(>\mathrm{N}-)$, and doubly coordinated nitrogen bonded to phosphates $(=\mathrm{N}-)$. There is also an unidentified fourth peak. The fractions of each form of nitrogen bonding and the $(>\mathrm{N}-) /(=\mathrm{N}-)$ ratio are also given in Table 3, in atomic percent of the overall film composition. Table 4 provides the similar deconvolution results of the phosphorus into $\mathrm{PO}_{4}{ }^{3-}$ and reduced phosphorous and the similar deconvolution of the oxygen into bridging and non-bridging oxygen bonding.

The density and composition data in Tables 1 and 2 were used to calculate the molar volume for each sample, and this is presented in Table 5.

\section{Discussion}

\subsection{Substrate Bias Power:}

LiPON film samples $A$ to $E$ were processed by varying substrate bias power while using common conditions of a room temperature deposition and 5 mTorr of nitrogen process gas. While initially explored to improve adhesion, the use of substrate bias had a significant effect on the LiPON film properties as well as the deposition process itself. As shown in Figure 6a), the 
ionic conductivity increased with bias power. The increase of ionic conductivity for the samples deposited at room temperature was from less than $1.0 \times 10^{-6} \mathrm{~S} / \mathrm{cm}$ for $0 \mathrm{~W}$ and $5 \mathrm{~W}$ of bias, reaching values of $\sim 1.8 \times 10^{-6} \mathrm{~S} / \mathrm{cm}$ and $1.9 \times 10^{-6} \mathrm{~S} / \mathrm{cm}$ for $10 \mathrm{~W}$ and $20 \mathrm{~W}$ of bias respectively. For the samples deposited at $300^{\circ} \mathrm{C}$, the increase was from less than $1.0 \times 10^{-6} \mathrm{~S} / \mathrm{cm}$ for $0 \mathrm{~W}$ bias to $\sim 3.7 \times 10^{-6} \mathrm{~S} / \mathrm{cm}$ for $20 \mathrm{~W}$ bias. This increase in ionic conductivity correlates with increases in the Li/P ratio measured by ICP OES shown in Table 2 and by the $\mathrm{Li}$ (LiPON bonding) to $\mathrm{P}$ (LiPON bonding) ratio measured by XPS shown in Tables 3 and 4 . As the ionic conductivity of LiPON can be considered the product of the $\mathrm{Li}$ ion density times the Li ion mobility[6], a higher $\mathrm{Li}$ ion concentration can be expected to correlate to higher ionic conductivity.

The applied bias caused other changes in the films. It did provide homogeneous adhesion of the film to the substrate, equivalent at the inner diameter and outer diameter. However, it also caused significant resputtering of the film material from the substrate surface. At the highest bias power (20W) examined, approximately half of the LiPON deposited was removed during deposition due to this resputtering, reducing the net film deposition rate. While the deposition rate decreased drastically with bias power, the change in the film density of the deposited film was relatively unchanged as shown in Table 1. On the other hand, the Li/P atomic ratio as measured by ICP/OES increased with bias power. The change in the phosphorus content that is possible in stable amorphous phosphate networks $\left(\mathrm{PO}_{3}\right.$ to $\left.\mathrm{PO}_{4}\right)$ is relatively small (less than 25 atomic percent). Hence, the increase in the ICP/OES Li/P ratio from 2.98 to 4.54 (a $~ 50 \%$ increase) should be interpreted as an increase in the lithium concentration in the film, and this is weakly supported by the XPS measurements of Li concentration. Note that a $\mathrm{Li} / \mathrm{P}$ atomic ratio of 3.0 is expected for an ideal $\mathrm{PO}_{4}$ network $\left(\mathrm{Li}_{3} \mathrm{PO}_{4}\right)$ while an atomic ratio of 1.0 is expected for an ideal $\mathrm{PO}_{3}$ network $\left(\mathrm{LiPO}_{3}\right) \cdot[11]$ The increase in the lithium concentration with increasing resputtering of the depositing film is expected due to 
the lower sputtering yield of lithium compared to phosphorus, estimated at $37.8 \%$ of the phosphorus yield.[43] These trends indicate the significant role that substrate bias has in modifying the structure and composition of LiPON thin films.

The activation energy for lithium ion conduction generally decreases with substrate bias, as shown in Figure 6b). It is possible that the slightly lower density amorphous network obtained at intermediate bias power (10W) allowed greater opportunities for lithium ion mobility and hence higher conductivity and lower activation energy. Note that the conductivity was similarly high at $10 \mathrm{~W}$ and $20 \mathrm{~W}$ of bias while the Li/P ratio observed by ICP-OES increased consistently with increasing bias, suggesting that the mobility of lithium ions may also be a factor in these films.

The increased $\mathrm{N}_{2}$ ion bombardment and resputtering due to the increasing substrate bias also caused a change in the stress state of the film. A mild compressive stress of $-8 \mathrm{MPa}$, observed for the sample deposited without substrate bias (OW), increased to a more compressive value of $-205 \mathrm{MPa}$ for the sample deposited at $20 \mathrm{~W}$ substrate bias, as given in Table 1. The LiPON films processed at the intermediate substrate bias condition of $10 \mathrm{~W}$ exhibited good adhesion, modest stress, and high ionic conductivity, and this was taken as the optimized bias condition for further experiments with deposition temperature and variation in the nitrogen gas pressure. The results are presented in the succeeding sections.

\subsection{Pressure effects at $10 \mathrm{~W}$ substrate bias condition:}

Higher $\mathrm{N}_{2}$ gas pressures of 10 mTorr and 15 mTorr were tested at the $10 \mathrm{~W}$ substrate bias condition and room temperature deposition to compare to the films deposited at 5 mTorr of $\mathrm{N}_{2}$. The deposition rate decreased with increasing process gas pressure, as given in Table 1 . The Li/P atomic ratio, as measured by ICP/OES, increased with gas pressure. The decrease in the ionic conductivity at higher pressures was accompanied by an increase in the activation 
energy for ionic conduction and a slight increase in compressive stress. No significant advantage to higher deposition pressures was observed.

(a)

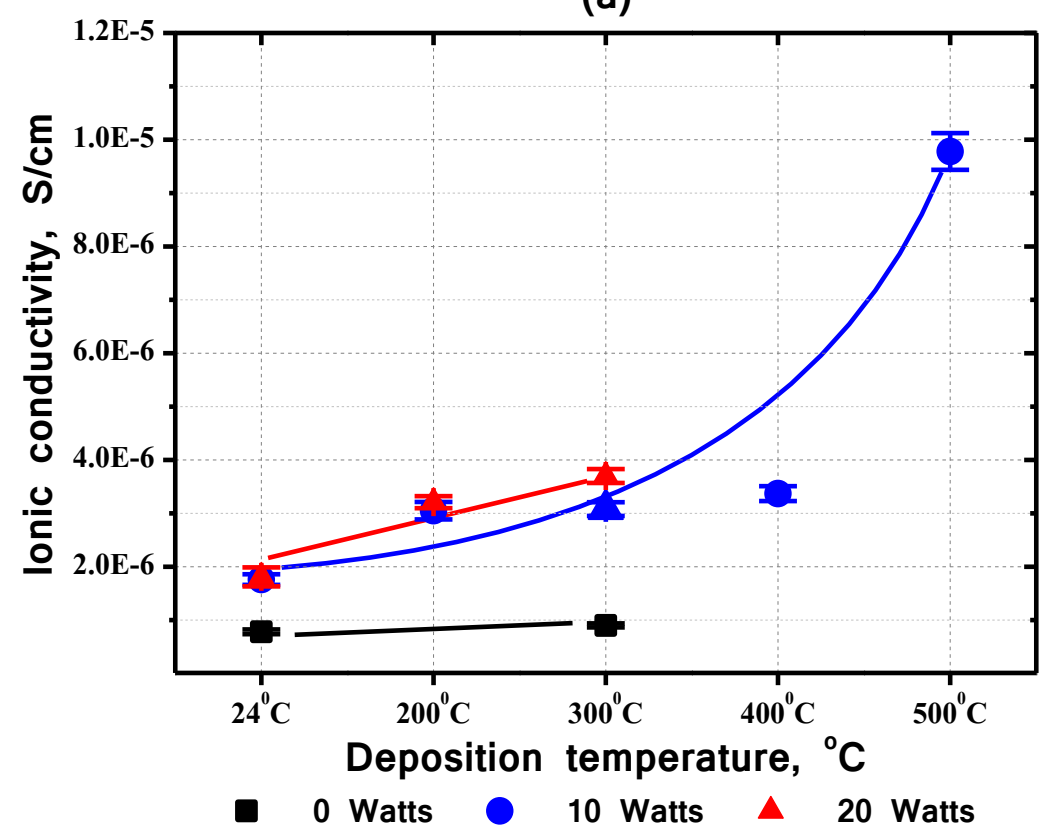

(b)

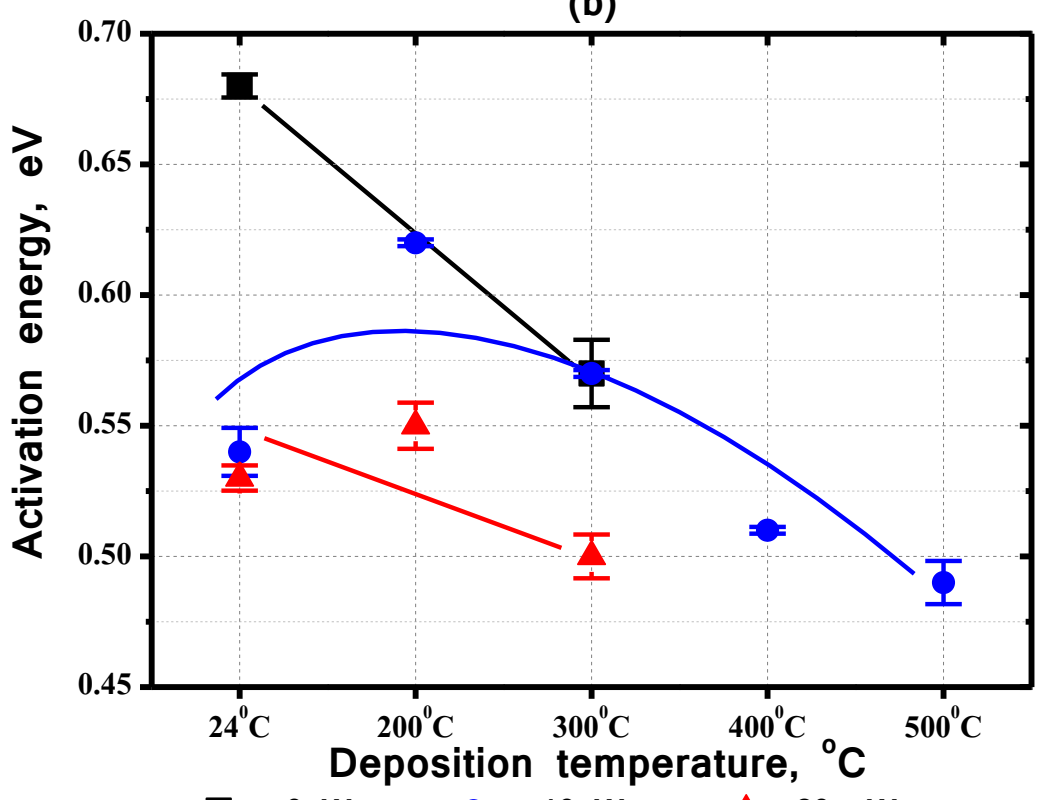

0 Watts 10 Watts $\triangle 20$ Watts

Figure 7. Inset (a) shows the ionic conductivity and inset (b) the activation energy of ionic conduction for LiPON films as a function of deposition temperatures. Please note that the lines are shown to guide the eye. 
(a)

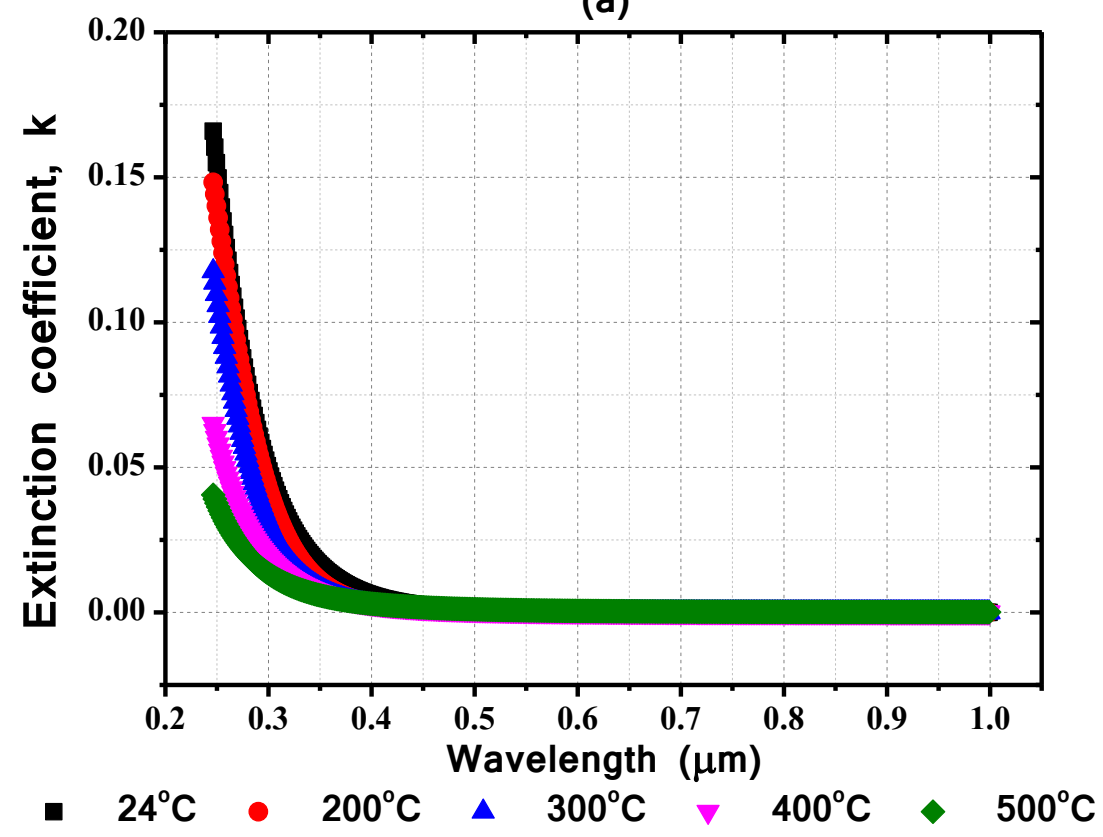

Figure 8 shows the optical extinction coefficient.

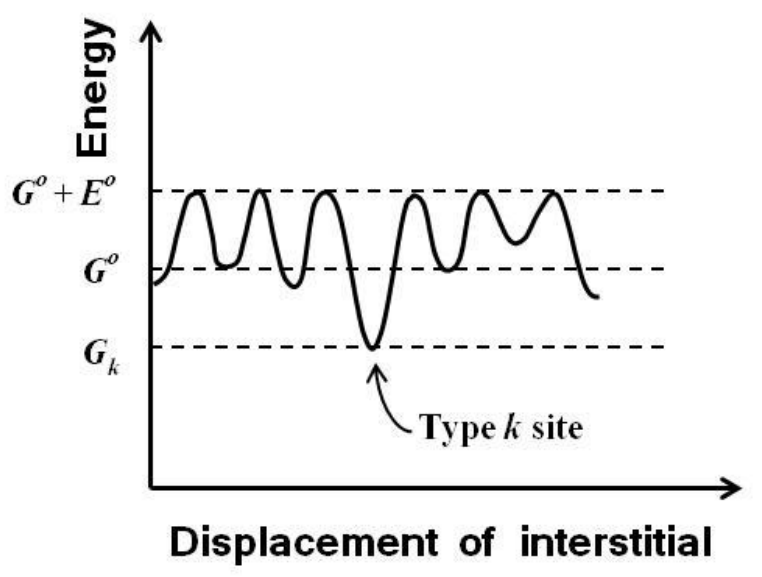

(a)

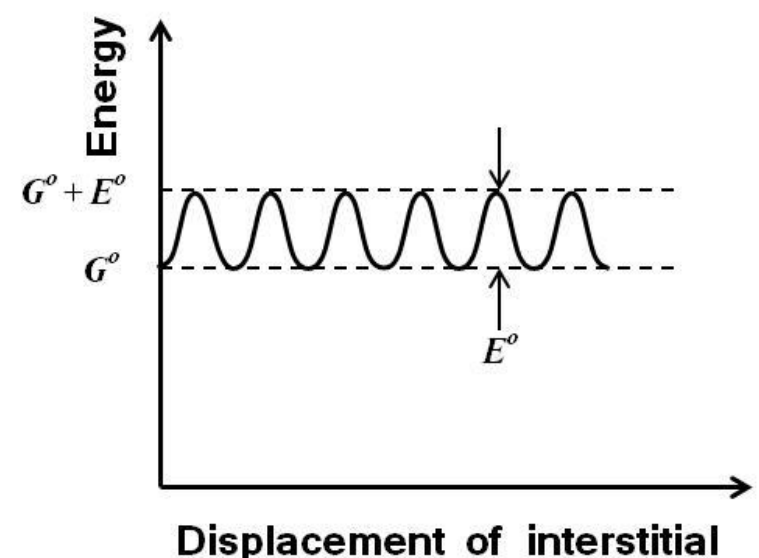

(b)

Figure 9_(a) The energy variation of an amorphous glass with the displacement of a diffusing interstitial atom ( $\mathrm{Li}^{+}$in LiPON) as it jumps between successive interstitial sites of varying energy levels. The type $k$ site shown in the picture is at a typical lowest energy or a deep trap site. (b) A plot similar to (a) for interstitial jumping in an idealized or ordered material containing only the sites of equal energy states state and having activation energies corresponding to $\mathrm{E}^{\circ}$. (Reproduced, by permission, from John and Wiley Sons Inc., "Kinetics of Materials", by Robert W. Balluffi, Samuel M. Allen, W. Craig Carter, Chapter 10 Diffusion in Noncrystalline Materials, Figure 10.4, p235. Copyright $\odot 2005$ by John Wiley \& Sons, Inc.)[47] 


\subsection{Deposition temperature effects at $10 \mathrm{~W}$ bias condition:}

The significant effect of the energetic bombardment associated with substrate bias on the structure and properties of LiPON films motivated a study of increasing energy at the atomic scale by increasing temperature during deposition. Specifically, higher deposition temperature is expected to enhance the mobility of adatoms on the surface of the depositing film and result in a structure having a lower defect density that is closer to the metastable equilibrium of an amorphous phase.[44] Hence, using a 10W substrate bias power, the sample deposition temperature was increased from room temperature to the range of $200^{\circ} \mathrm{C}$ to $500^{\circ} \mathrm{C}$. As expected, deposition temperature did have a significant effect on the LiPON film deposition, composition, structure, and properties. The residual stress at room temperature in the LiPON films changed from a weakly compressive stress (-159 MPa) to tensile (266 MPa) for the Samples C and I, respectively, as shown in Table 1. This increase in tensile residual stress is primarily due to the mismatch in the thermal expansion coefficients of the LiPON film $\left(\sim 15 \times 10^{-6}\right.$ $\left.{ }^{\circ} \mathrm{C}^{-1}\right)$ [45] with the silicon substrate $\left(2.6 \times 10^{-6}{ }^{\circ} \mathrm{C}^{-1}\right)$ resulting in tensile strain upon cooling to room temperature from the elevated deposition temperature. More interestingly, the ionic conductivity increased by an additional factor of five at the highest deposition temperature explored $\left(500^{\circ} \mathrm{C}\right)$ to a maximum of $9.8 \times 10^{-6} \mathrm{~S} / \mathrm{cm}$. The increased ionic conductivity was accompanied by a decrease in the activation energy for ionic conduction, to a minimum of $0.49 \mathrm{eV}$, consistent with an improved mobility for the Li ion in the LiPON matrix. The variations in the ionic conductivity and activation energy of the LiPON films deposited at different temperatures are given in Table 1 and shown in Figure 7.

The increase in ionic conductivity with deposition temperature was not accompanied by an increase in excess volume of the LiPON amorphous matrix, as might be associated with an increased Li ion mobility. Rather, as shown in Table 5 and Figure 10a), the molar volume decreased with increased temperature. This is supported by increases in both the film density 
and refractive index. For example, the molar volume of Sample I, deposited at $500^{\circ} \mathrm{C}$, was 6.47 $\mathrm{cm}^{3} / \mathrm{mol}$ atoms compared to that of sample $\mathrm{C}$, deposited at room temperature, which was 7.11 $\mathrm{cm}^{3} / \mathrm{mol}$ atoms. This is a decrease of $\sim 10 \%$ in molar volume and is consistent with the density increase between the two samples of $\sim 18 \%$. Table 1 also provides the refractive index at $999 \mathrm{~nm}$ wavelength, which increased by $2.35 \%$. The optical properties of LiPON films, extinction coefficient (k), deposited at different temperatures are shown over a range of wavelengths in Figure 8. The decrease in excess volume observed is expected for amorphous films processed at higher temperatures,[46] but does not explain the increase in ionic conductivity, as a decrease in atomic mobility with decreased excess volume is generally expected for amorphous films.[47] Figure 10a) also shows the increasing trend in ionic conductivity with deposition temperature to contradict that of molar volume.

The increase in ionic conductivity with deposition temperature can also not be explained by an increase in the Li concentration of the films. Rather, a decrease in the Li concentration is observed with increase in the deposition temperature. This is evident in the Li/P atomic ratio measured by ICP/OES and by XPS given in Table 2. While both Li and P adatoms may be expected to have higher desorption rates from the LiPON film surface at higher temperatures, this effect is expected to be more pronounced for $\mathrm{Li}$ adatoms due to the weaker bonding of $\mathrm{Li}$ to the oxide matrix (dissociation energy for $\mathrm{Li}-\mathrm{O}$ bond at $\mathrm{OK}$ is $331.0 \mathrm{kcal} / \mathrm{mol}$, while the dissociation energy for a P-O bond is $592.0 \mathrm{kcal} / \mathrm{mol}$ ).[48] The decrease in Li content (and presumably, Li ion density) may also be expected to result in a reduced ionic conductivity, but this is not the case. The trends of Li/P atomic ratio, molar volume, and the ionic conductivities with respect to the deposition temperatures are shown in Figure 10a).

Previous authors have suggested that the increases in the ratio of triply coordinated nitrogen to doubly coordinated nitrogen, $(>\mathrm{N}-) /(=\mathrm{N}-)$, correlate positively with ionic conductivity[3,5,6,9,11,19,20]. However, the results from the XPS data representative of the 


\begin{abstract}
LiPON electrolyte layer do not support this. As shown in Table 3, $(>\mathrm{N}-) /(=\mathrm{N}-)$ decreases with increasing deposition temperature and increasing ionic conductivity. The relatively low values of $(>\mathrm{N}-) /(=\mathrm{N}-)$ measured are consistent with the NMR study of Stallworth et al. wherein the triply coordinated nitrogen bonds was observed to be largely absent.[17]
\end{abstract}

(a)

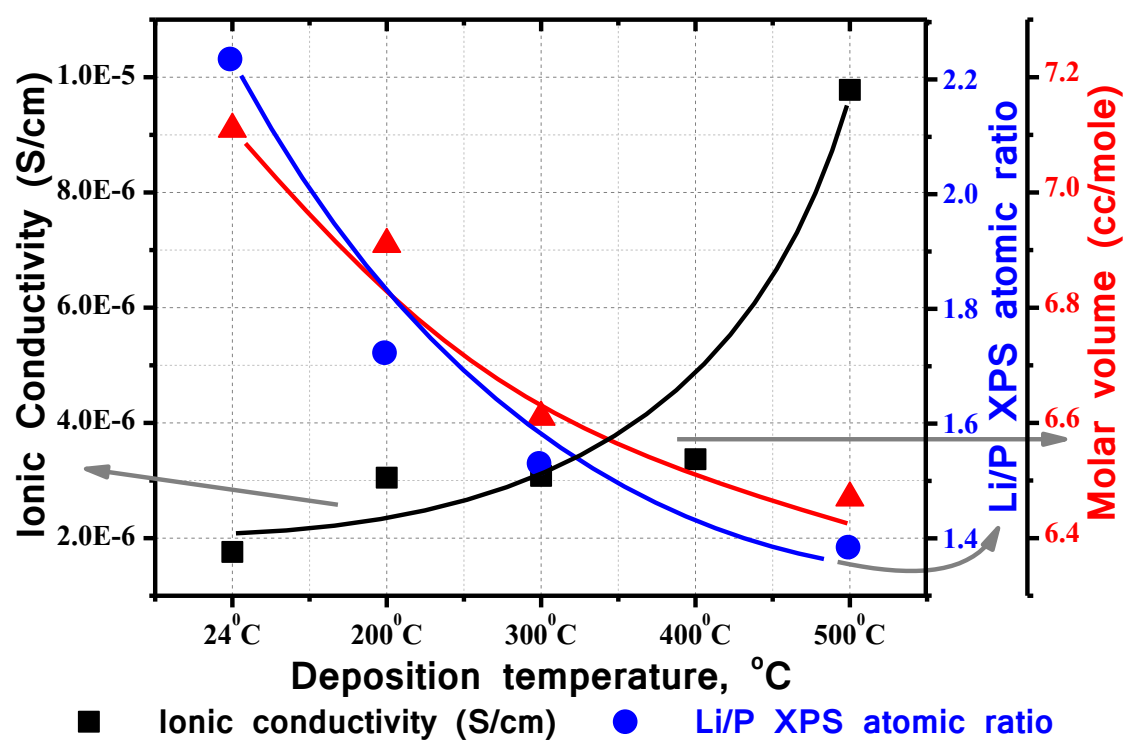

A Molar volume (cc/mole)

(b)

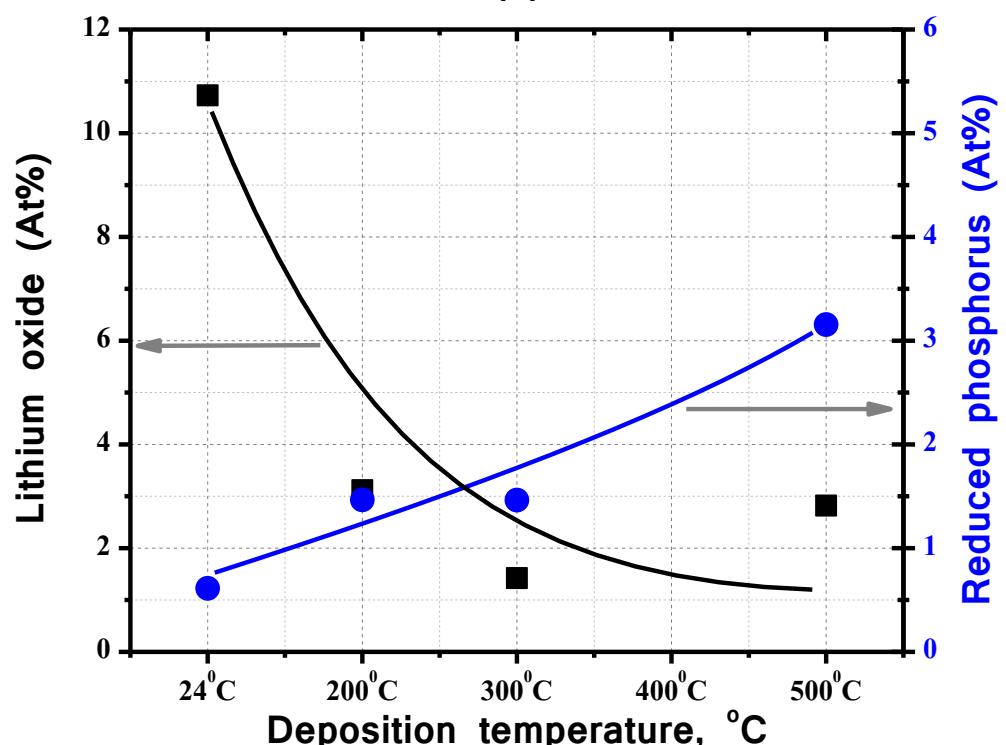

- Lithium oxide - Reduced phosphorus 
(c)

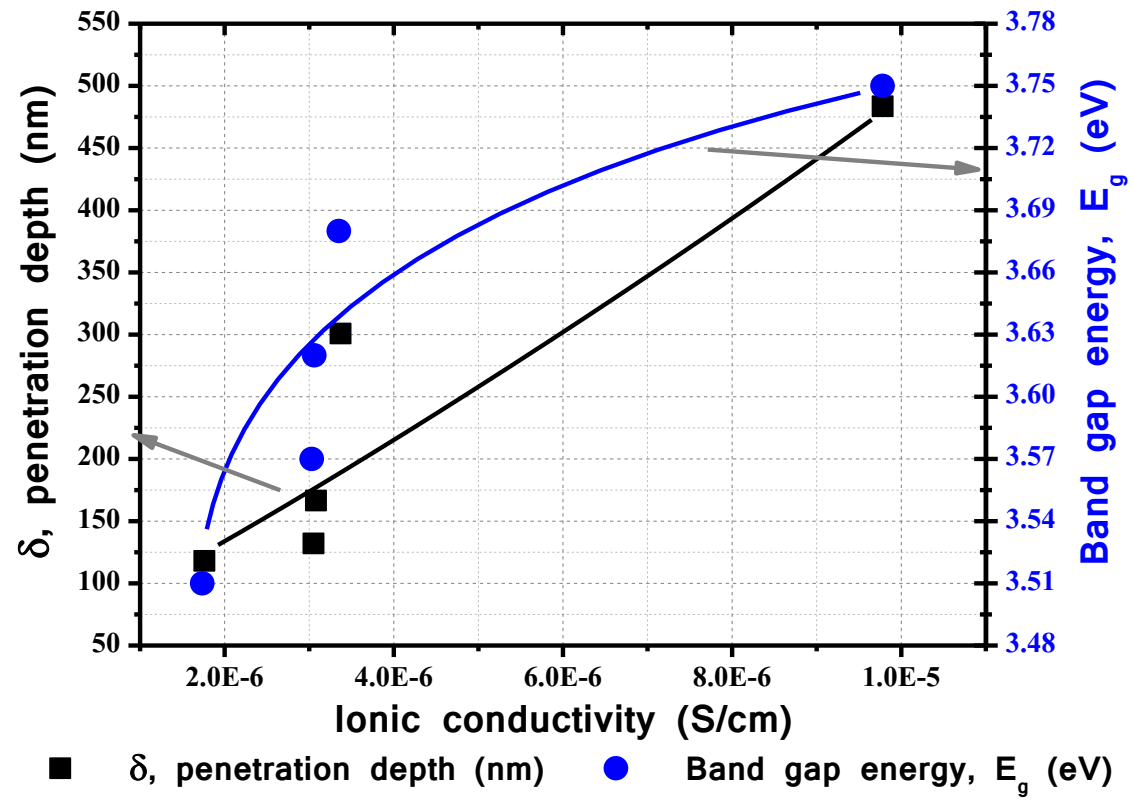

Figure 10 shows the characteristics of LiPON films deposited under different temperature conditions. Figure 11 (a) shows the increasing trend of the ionic conductivity, the decreasing trends of $\mathrm{Li} / \mathrm{P}$ atomic ratio measured by XPS and molar volume calculated from film density and atomic concentration. Figure 11 (b) shows a decreasing trend of lithium oxide, Li2O, and an increasing trend of reduced (metal-like) phosphorus with the increase of deposition temperatures. In Figure 11 (c) the correlation between penetration depth, $\delta,(\mathrm{nm})$ and the ionic conductivity is strong and almost linear. Please note that the curved lines are shown to guide the eye.

However, it should be noted that the nitrogen concentration shows a steady increase with deposition temperature, as shown in Table 3. The total nitrogen percentage increases from $4.1 \%$ at room temperature to $10.3 \%$, at $500^{\circ} \mathrm{C}$, more than doubling as the ionic conductivity increases from $1.8 \times 10^{-6}$ to $9.8 \times 10^{-6} \mathrm{~S} / \mathrm{cm}$. This is consistent with prior work that has identified nitrogen substitution can improve the ionic conductivity over that of pure $\mathrm{Li}_{3} \mathrm{PO}_{4}$ films.[1$8,10,13,42,45,49,50]$

Another trend in LiPON film chemistry with deposition temperature is the tendency for the higher deposition temperature to result in films with a more strongly reducing and less oxidizing chemistry. The non-LiPON atomic percentages for $\mathrm{Li}, \mathrm{N}, \mathrm{O}$, and $\mathrm{P}$ given in Tables 3 and 4 (derived from the high resolution spectra) can be summed to determine the percentage of 
non-LiPON bonding in the films. The non-LiPON bonding in films deposited at room temperature ranged from $10 \%$ to $22 \%$ while that of films deposited at higher temperatures ranged from $3 \%$ to $11 \%$. Specifically, the increased deposition temperature resulted in a decrease in the Li-oxygen $\left(\mathrm{Li}_{2} \mathrm{O}\right)$ bonding and an increase in the reduced phosphorus bonding. These trends are shown in Figure 10b). This indicates that the films deposited at higher temperature were more reducing and less oxidative. This is consistent with a higher mobility of $\mathrm{Li}$ ions at the higher deposition temperature if it is presumed that the oxidative chemistry has a role in pinning Li and reducing ion mobility.

The reducing chemistry and increased nitrogen content observed at increased deposition temperature may interact with structural factors that influence ionic conductivity. Specifically, the density of point defects, such as broken/unsatisfied bonds, can be expected to impact ionic conductivity as trapping sites for $\mathrm{Li}$ ions. A uniform structure is known to increase internal diffusion in amorphous films as shown conceptually in Figure 9.[47] The increased uniformity of energy barriers for interstitial diffusion in an amorphous matrix that is shown in Figure 10b can be expected to similarly aid Li ion conduction in LiPON films of lower defect density. In amorphous semiconducting and insulating materials, an increase in the optical band gap is commonly observed with reduced point defects. The correlation of the optical band gap with ionic conductivity for the substrate temperature series of LIPON films is given in Figure 9c). Another measure of the defect density in the LiPON films is the optical penetration depth, $\delta$. If the optical scattering defects and $\mathrm{Li}$ ion pinning defects in the film are presumed proportional to one another in similarly processed films (i.e., same bias, pressure) then $\delta$ should also be proportional to the Li ion mobility in the film. Values for the $\delta$ are given in Table 1 (calculated at $246 \mathrm{~nm}$ ) and Figure 9c), which shows that the ionic conductivity and optical penetration depth do show a strong correlation for the deposition temperature series of samples, consistent with 
the increased deposition temperature providing a structural improvement in the LiPON amorphous matrix that allows a higher ionic mobility.

\section{Conclusions:}

In this work, substrate bias, deposition temperature, and sputtering process gas pressure were investigated in the deposition of LiPON thin films. Li ion conductivities in the $10^{-6}$ $\mathrm{S} / \mathrm{cm}$ range were obtained with a maximum of $9.8 \times 10^{-6} \mathrm{~S} / \mathrm{cm}$. These ionic conductivities substantially replicated that of previous workers, including the relatively high value of $9.1 \times 10^{-6}$ $\mathrm{S} / \mathrm{cm}$ reported by Chiu et al.

Ionic conductivity was found to increase modestly with substrate bias power for samples deposited at room temperature, but increasing the deposition temperature resulted in highest ionic conductivity.

Compositional and structural factors were considered to understand the trends in ionic conductivity observed. XPS depth profiling measurements of the ratio of triply coordinated to doubly coordinated nitrogen $(>\mathrm{N}-) /(=\mathrm{N}-)$ were made that did not support prior reports of a positive correlation of this ratio to ionic conductivity. Rather, the large and variable values of this ratio (from 0.3 to 3.3) previously reported were only observed in oxidized surface regions of the LiPON films, and depth profiling revealed that the ratio measured within the LiPON electrolyte layers was lower and did not positively correlate to ionic conductivity. The increased deposition temperature was found to result in decreases in atomic volume and in the Li content of the films that also did not positively correlate to the ionic conductivity. Compositionally, increases in the reduced phosphorous content and nitrogen content were found to positively correlate with ionic conductivity. Optical characterization of the LiPON film structure revealed that an increased effective band gap and penetration depth correlated positively with the increased ionic conductivity observed in the deposition temperature series. From this, it can be 
speculated that an important factor in amorphous solid state ionic conductors may be an increased uniformity of the amorphous network, such that it has fewer defect sites that can serve to trap Li ions. 


\section{Acknowledgments}

The authors would like to acknowledge Planar Energy Devices and the Department of Energy ARPA-E program, Award DE-AR0000064 for funding this project. We would like to thank Dr. J. Hickman, Candace Martin, Mikhail Klimov for their assistance with XPS depth profiling. We would also like to thank Niall Donnelly for useful discussions on ionic conductivity theory in solid state materials.

\section{References}

[1] X. Yu, J.B. Bates, G.E. Jellison-Jr., F.X. Hart, J. Electrochem. Soc. 144 (1997) 524-532.

[2] J.B. Bates, N.J. Dudney, G.R. Gruzalski, R.A. Zuhr, A. Choudhury, C.F. Luck, J.D. Robertson, Solid State lonics 53-56 (1992) 647-654.

[3] J.B. Bates, N.J. Dudney, G.R. Gruzalski, R.A. Zuhr, A. Choudhury, C.F. Luck, J.D. Robertson, J. Power Sources 43-44 (1993) 103-110.

[4] B. Wang, B.S. Kwak, B.C. Sales, J.B. Bates, J. Non. Cryst. Solids 183 (1995) 297-306.

[5] B. Wang, B.C. Chakoumakos, B.C. Sales, B.S. Kwak, J.B. Bates, J. Solid State Chem. 115 (1995) 313-323.

[6] N.-S. Roh, S.-D. Lee, H.-S. Kwon, Scr. Mater. 42 (2000) 43- 49.

[7] Y. Hamon, A. Douard, F. Sabary, C. Marcel, P. Vinatier, B. Pecquenard, A. Levasseur, Solid State lonics 177 (2006) 257-261.

[8] H.Y. Park, S.C. Nam, Y.C. Lim, K.G.. Choi, K.C. Lee, G.B. Park, H.P. Kim, S.B. Cho, J. Electroceramics 17 (2006) 1023-1030.

[9] T. Pichonat, C. Lethien, N. Tiercelin, S. Godey, E. Pichonat, P. Roussel, M. Colmont, P. Alain, Mater. Chem. Phys. 123 (2010) 231-235.

[10] B. Fleutot, B. Pecquenard, H. Martinez, M. Letellier, A. Levasseur, Solid State lonics 186 (2011) 29-36.

[11] F. Vereda-Moratilla, A Study of the Thin Film Battery Electrolyte Lithium Phosphorus Oxynitride Deposited by an Ion Beam Assisted Process, Tufts University, 2003. 
[12] Y.G. Kim, Plasma-Assisted Directed Vapor Deposition for Synthesizing Lithium Phosphorus Oxynitride Thin Films, University of Virginia, 2008.

[13] W.-Y. Liu, Z.-W. Fu, C.-L. Li, Q.-Z. Qin, Electrochem. Solid-State Lett. 7 (2004) J36-J40.

[14] K.-F. Chiu, C.C. Chen, K.M. Lin, C.C. Lo, H.C. Lin, W.-H. Ho, C.S. Jiang, J. Vac. Sci. Technol. A Vacuum, Surfaces, Film. 28 (2010) 568-572.

[15] I. Seo, Preparation and Characterization of Lithium Thio- Germanate Thin Film Electrolytes Grown by RF Sputtering for Solid State Li-lon Batteries, lowa State University, 2009.

[16] N. Kamaya, K. Homma, Y. Yamakawa, M. Hirayama, R. Kanno, M. Yonemura, T. Kamiyama, Y. Kato, S. Hama, K. Kawamoto, A. Mitsui, Nat. Mater. 10 (2011) 682-686.

[17] P.E. Stallworth, F. Vereda, S.G. Greenbaum, T.E. Haas, P. Zerigian, R.B. Goldner, J. Electrochem. Soc. 152 (2005) A516.

[18] P.D. Mani, A. Vijayakumar, M.-P. Real-Robert, S.J. Duranceau, K.R. Coffey, Characterisation of Reactively Sputter Deposited Lithium Phosphorus Oxy-Nitride Thin Films, 218 ${ }^{\text {th }}$ Electro-Chemical Society meeting, Las Vegas, 2010.

[19] Z. Hu, D. Li, K.A.I. Xie, Bull. Mater. Sci. 31 (2008) 681-686.

[20] Y.G. Kim, H.N.G. Wadley, J. Vac. Sci. Technol. A 26 (2008) 174-183.

[21] JA Woollam Inc.,, WVASE 32 software.

[22] C.M. Herzinger, B. Johs, W.A. McGahan, J.A. Woollam, W. Paulson, J. Appl. Phys. 83 (1998) 3323-3336.

[23] J.A. Woollam Inc., Guide to using WVASE32.

[24] H.G. Tompkins, WVASE 32 Software training manual, 2008.

[25] V.L.. Bonch-Bruevich, Sov. Phys. Uspekhi 26 (1983) $664-695$.

[26] F. Urbach, Phys. Rev. 92 (1953) 1324.

[27] J.. Tauc, Mater. Res. Bull. 5 (1970) 721-729.

[28] G. Stoney, Proc. R. Soc. London 82 (2013) 172-175.

[29] M.A. Hopcroft, W.D. Nix, T.W. Kenny, J. Microelectromechanical Syst. 19 (2010) 229238.

[30] Scribner Associates Inc., ZView software.

[31] J. Jamnik, J. Maier, J. Electrochem. Soc. 146 (1999) 4183-4188. 
[32] W. Lai, S.M. Haile, J. Am. Ceram. Soc. 88 (2005) 2979-2997.

[33] N.J. Donnelly, C.A. Randall, Appl. Phys. Lett. 96 (2010) 052906-1 - 052906-3.

[34] Casa software Ltd, CasaXPS: Processing software for XPS, AES, SIMS and more.

[35] B. Fleutot, B. Pecquenard, H. Martinez, A. Levasseur, Solid State lonics 206 (2012) $72-$ 77.

[36] Y.-C. Lu, E.J. Crumlin, G.M. Veith, J.R. Harding, E. Mutoro, L. Baggetto, N.J. Dudney, Z. Liu, Y. Shao-Horn, Sci. Rep. 2 (2012) 1-6.

[37] S. Tanaka, M. Taniguchi, H. Tanigawa, J. Nucl. Mater. 283-287 (2000) 1405-1408.

[38] A. Thißen, D. Ensling, M. Liberatore, Q.-H. Wu, F.J.F. Madrigal, M.S. Bhuvaneswari, R. Hunger, W. Jaegermann, lonics 15 (2009) 393-403.

[39] C.E. Myers, H.F. Franzen, J.W. Anderegg, Inorg. Chem. 24 (1985) 1822-1824.

[40] T.P. Moffat, R.M. Latansion, R.R. Ruf, Electrochim. Acta 40 (1995) 1723-1734.

[41] R.K. Brow, J. Non. Cryst. Solids 263-264 (2000) 1-28.

[42] R. Marchand, D. Agliz, L. Boukbir, A. Quemerais, J. Non. Cryst. Solids 183 (1988) 297306.

[43] M. Ohring, Materials Science of Thin Films, Second Ed., Academic Press, San Diego, 2002, p. 177.

[44] M. Ohring, Materials Science of Thin Films, Second Ed., Academic Press, San Diego, 2002, p. 495.

[45] R.W. Larson, D.E. Day, J. Non. Cryst. Solids 88 (1986) 97-113.

[46] F. Demichelis, G. DellaMea, G. Crovini, C.F. Pirri, E.Tresso, E. Giamello, Phys. B Condens. Matter 170 (1991) 149-152.

[47] R.W. Balluffi, S.M. Allen, W.C. Carter (Eds.), Kinetics of Materials, John Wiley \& Sons, Inc., New Jersey, 2005, pp. 229-247.

[48] B. deB. Darwent, Bond Disassociation Energy in Simple Molecules, National Standard Reference Data Service - National Bureau Standards (U.S.) 31 (1970), 1-48.

[49] H. Rabaa, H. Roald, J. Solid State Chem. 145 (1999) 619-628.

[50] Y. Hamon, P. Vinatier, E.I. Kamitsos, M. Dussauze, C.P.E. Varsamis, D. Zielniok, Solid State lonics 179 (2008) $1223-1226$. 